\title{
Comparison of the Performance of ANN and SVM Methods in Rainfall- Runoff Process Modeling (Case Study: North Karun Watershed)
}

\author{
S. H. Roshun ${ }^{1}$, K. Shahedi ${ }^{*}$, M. Habibnejad Roshan ${ }^{1}$ and J. Chormanski ${ }^{2}$
}

(Received: April 22-2020; Accepted: September 28-2020)

\begin{abstract}
The simulation of the rainfall-runoff process in the watershed has particular importance for a better understanding of hydrologic issues, water resources management, river engineering, flood control structures, and flood storage. In this study, to simulate the rainfall-runoff process, rainfall and discharge data were used in the period 1997-2017. After data qualitative control, rainfall, and discharge delays were determined using the coefficients of autocorrelation, partial autocorrelation, and cross-correlation in R Studio software. Then, the effective parameters and the optimum combination were determined by the Gamma test method and used to implement the model under three different scenarios in MATLAB software. Gamma test results showed that today's precipitation parameters, precipitation of the previous day, discharge of the previous day, and discharge of two days ago have the greatest effect on the outflow of the basin. Also, the $\mathrm{P}_{t} \mathrm{Q}_{\mathrm{t}-1}$ and $\mathrm{P}_{\mathrm{t}} \mathrm{P}_{\mathrm{t}-1} \mathrm{Q}_{\mathrm{t}-1} \mathrm{Q}_{\mathrm{t}-2} \mathrm{Q}_{\mathrm{t}-3}$ combinations were selected as the most suitable input combinations for modeling. The results of the modeling showed that in the support vector machine model, the Radial Base kernel Function (RBF) has a better performance than multiple and linear kernels. Also, the performance of the Artificial Neural Network model (ANN) is better than the Support Vector Machine model (SVM) with Radial Base kernel Function (RBF).
\end{abstract}

Keywords: Gamma test, Optimum combination, Soft calculations, Artificial neural network, Support vector machine, North Karun watershed

1. Watershed Management Engineering, Sari Agricultural Sciences and Natural Resources University. Mazandaran, Iran.

2. Faculty of Civil and Environmental Engineering, Warsaw University of Life Sciences, Warsaw, Poland.

Corresponding author, Email: kaka.shadehi@gmail.com 


\section{مقايسه عملكرد روشهاى هوش مصنوعى ANN و SVM در مدلسازى فرايند بارش - رواناب (مطالعه موردى: حوضه آبخيز كارون شمالى)}

سيدحسين روشان'، كاكا شاهدى'"، محمود حبيبنزاد روشن' و ياروسلاو كرمانسكى'

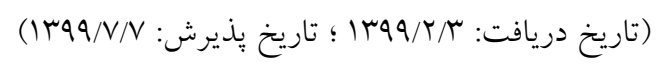

جكيده

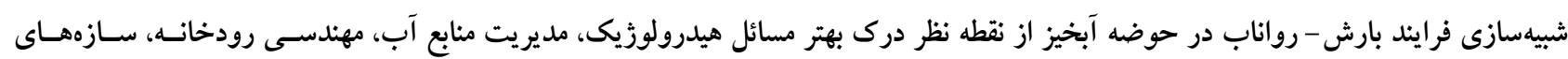

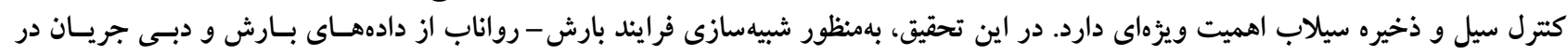

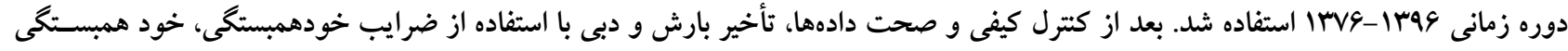

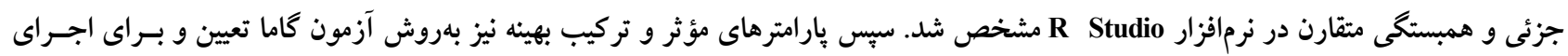

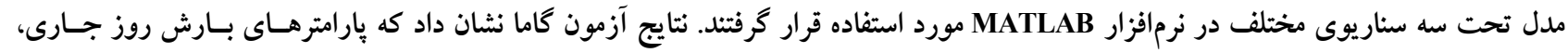

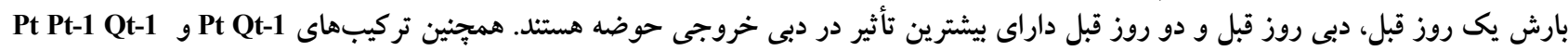

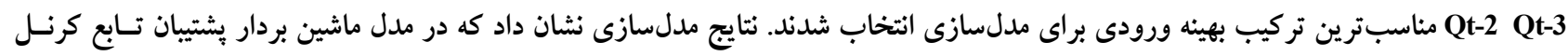

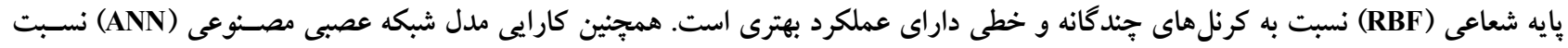

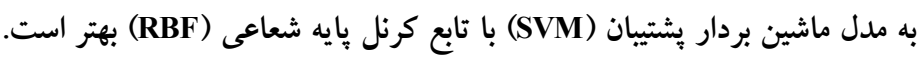

وازههاى كليدى: آزمون كاما، تركيب بهينه، محاسبات نرم، شبكه عصبى مصنوعى، ماشين بردار بشتيبان، حوضه آبخيز كارون شمالى 
(Machine )، شبكه فازى - عصبى تطبيقى (ANFIS)، رگرسيون

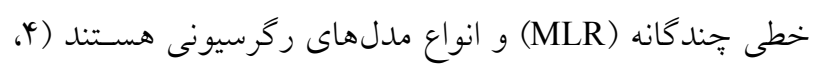

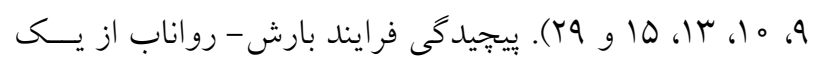

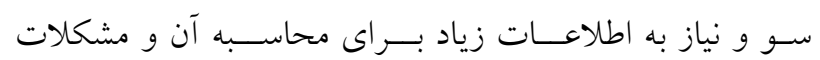

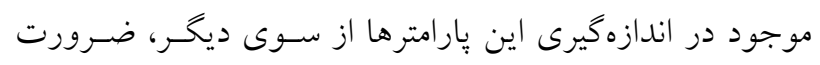

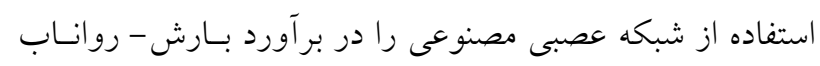

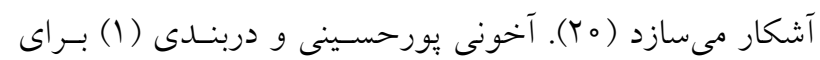

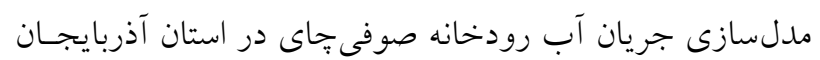
از مدل هاى شـبكه عصسبى مصسنوعى و ماشـين بـردار يشـتيبان

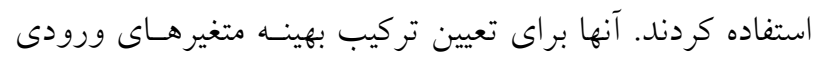

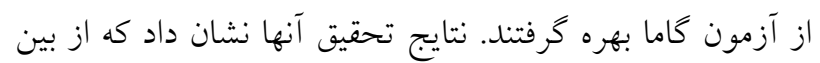

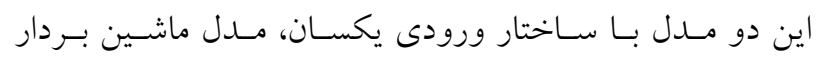

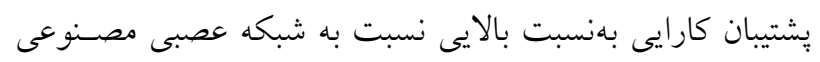

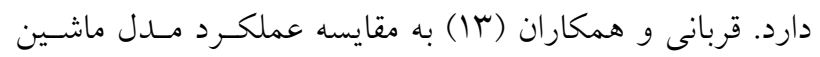

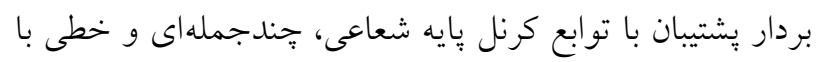

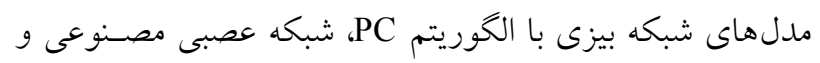

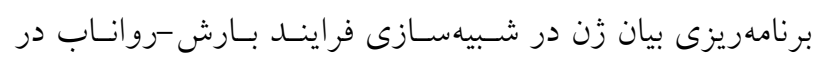

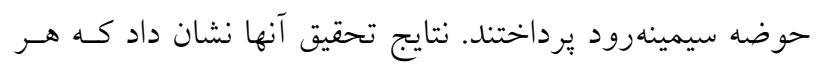

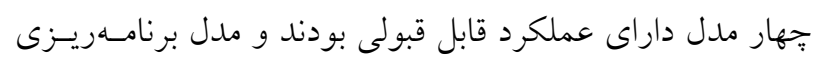

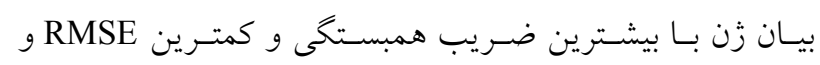

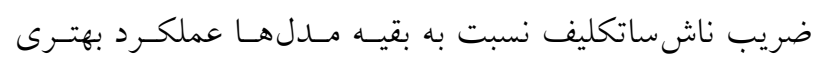

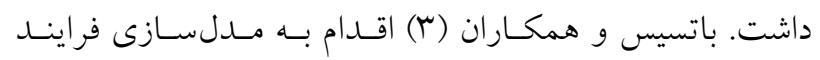

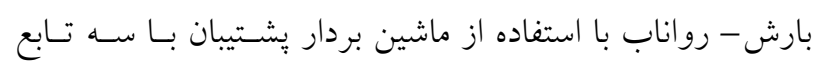

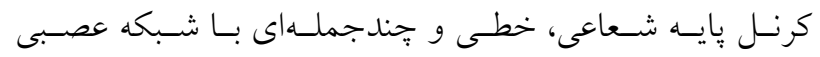

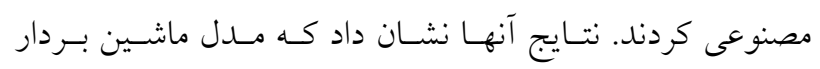

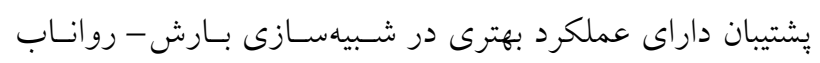

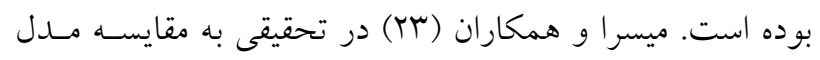

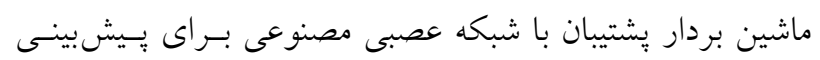

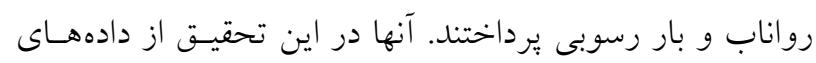
روزانه، هفتخى و ماهانه جريان و رسوب استفاده كردنـــ نتسايج

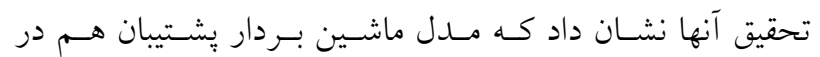

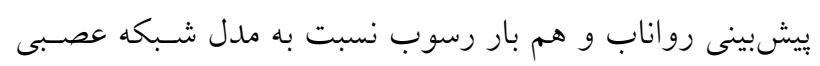

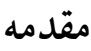

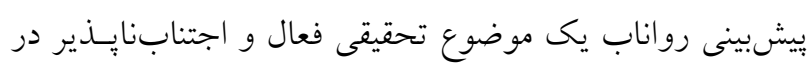

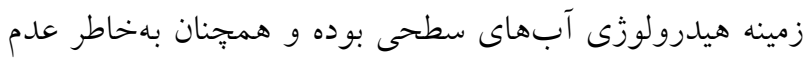

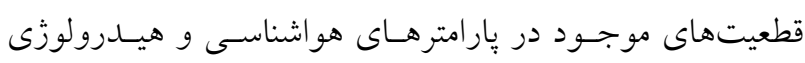

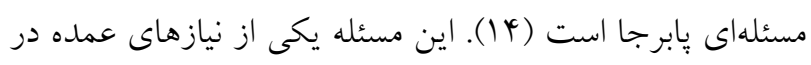

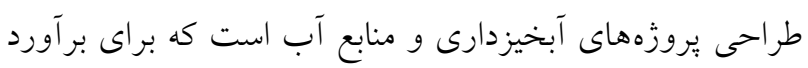

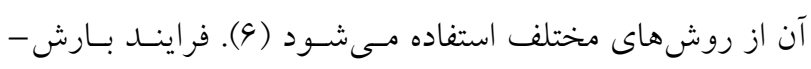

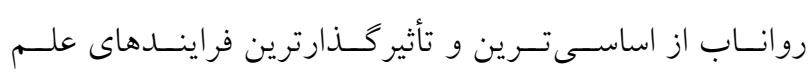

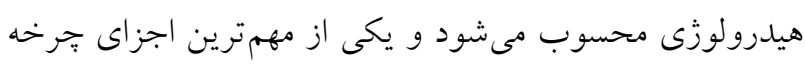

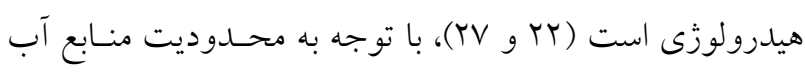

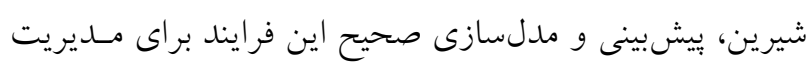

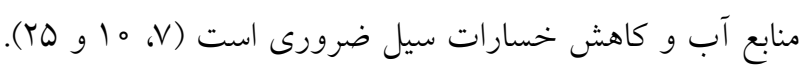

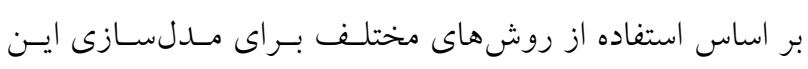

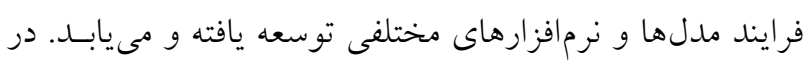

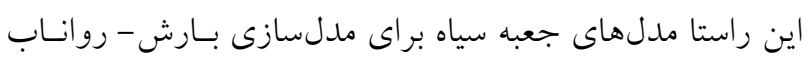

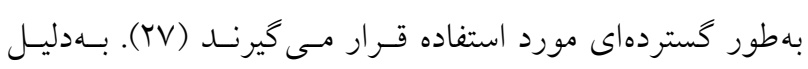

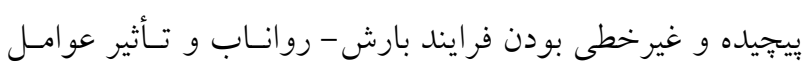

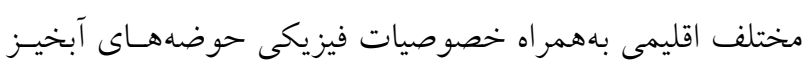

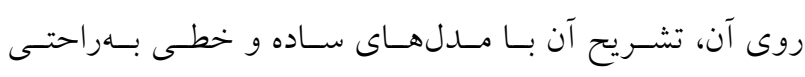

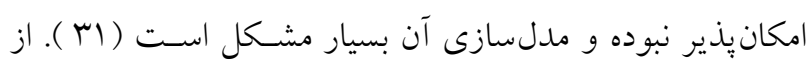

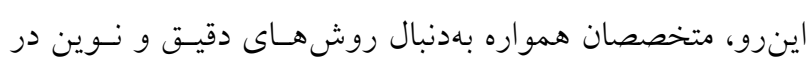

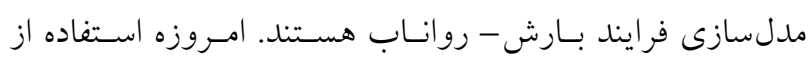

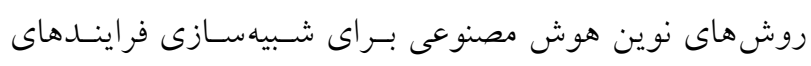

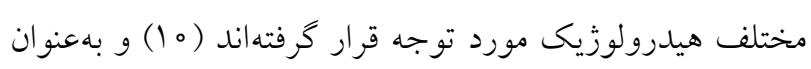

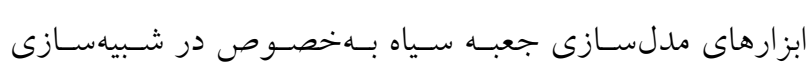

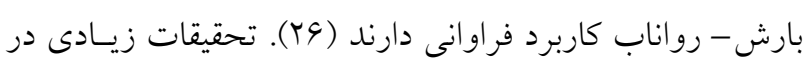

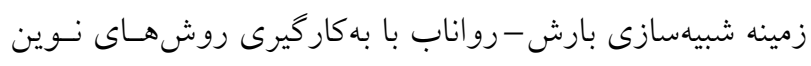

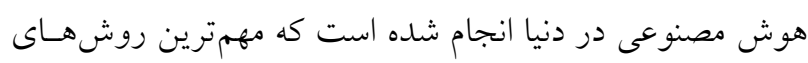

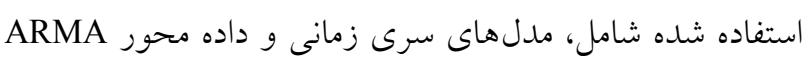

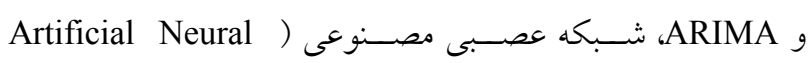

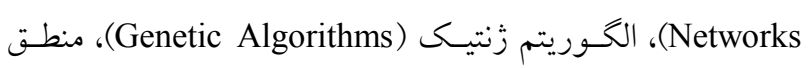
فازى (Fuzzy Logic)، ماشين بردار يشـيبان ( Support Vector) 
آزمون ران تست مورد بررسى قرار گرفت.

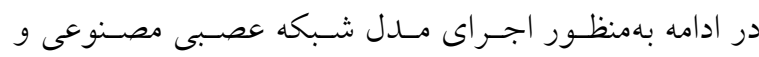

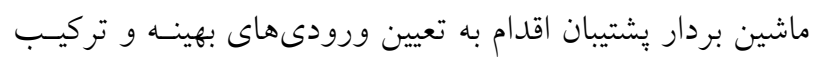

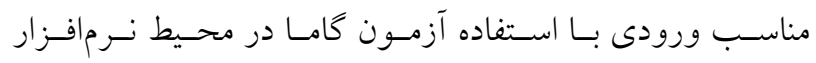

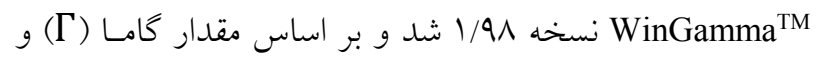
خطاى استاندارد پيارامترهاى ورودى و تركيب بهينه انتخاب شد.

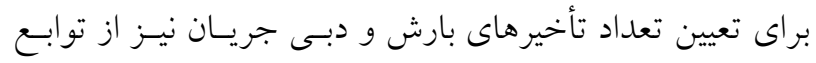

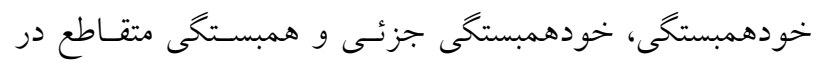
محيط نرم|فزار Rtudio بهره خرفته شد.

آزمون كاما

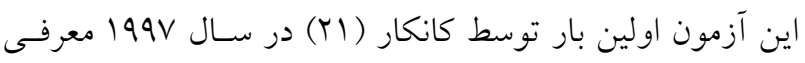

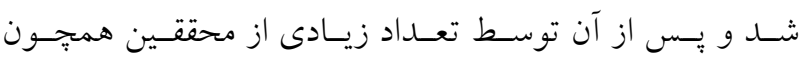
دورانت (1) (1)، توسى (Yr) و جــونز و همكــاران (19) جزئيـات

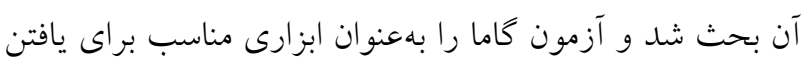

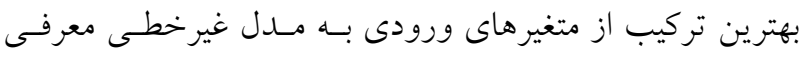

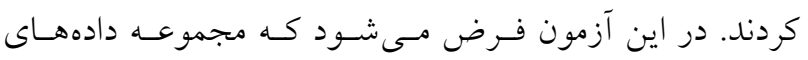
مشاهداتى بهصورت رابطه است (1) (1): $\left\{\left(\mathrm{x}_{\mathrm{i}}-\mathrm{y}_{\mathrm{i}}\right), 1 \leq \mathrm{i} \leq \mathrm{M}\right\}$

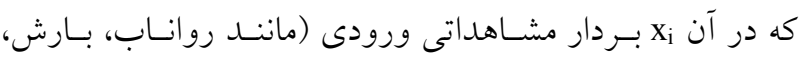

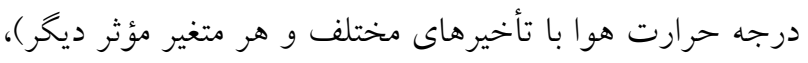

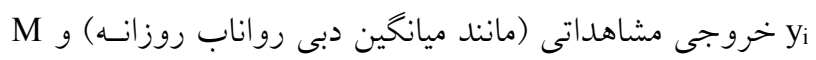
تعداد كل مشاهدات اسـت. از بـردار Xi ( در فضـاى m بعـدى) براى مدلسازى (yi در فضاى R استفاده مىشـود. بنـابراين، بـا

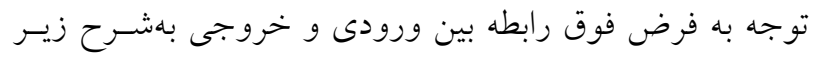

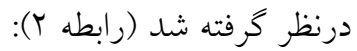
$y=f(x)+r$

كه در آن f يك تابع هموار و r متغير تصادفى نشاندهنــده خطـا

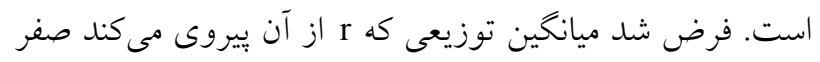

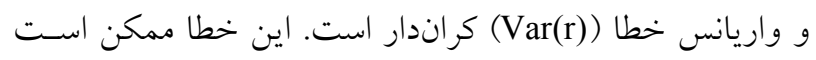

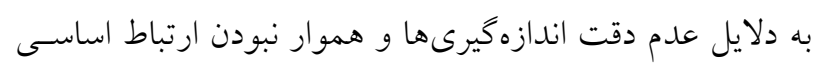

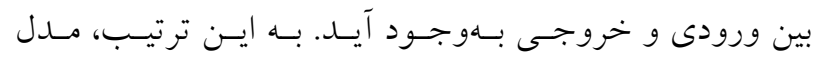

مصنوعى عملكرد بهتـرى داشـته اسـت. هــدف تحقيـق حاضـر مقايسه دو مدل شبكه عصبى مصنوعى و ماشين بــردار يشـتيبان

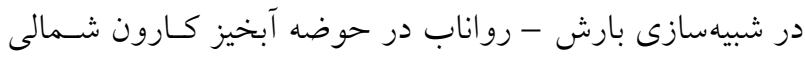

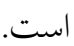

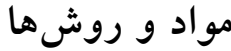

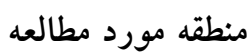

حوضه آبخيز كارون بزرى يكى از مب مورده حوضه آبخيـز درجسه دو

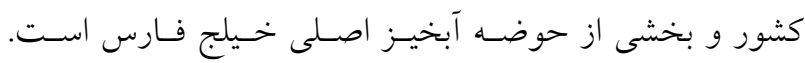

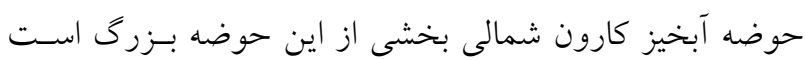

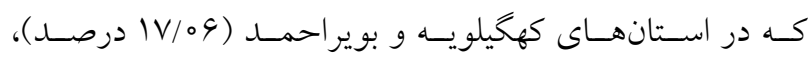

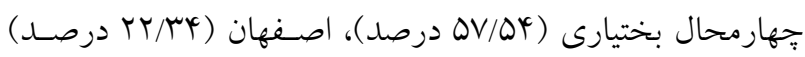
خوزستان (1/V0) و بخشى از فارس (4/ ا درصد) كستره دارد.

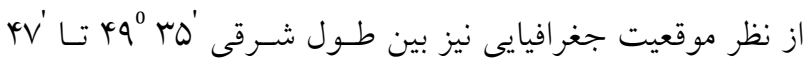

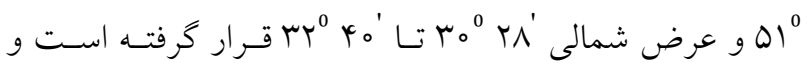

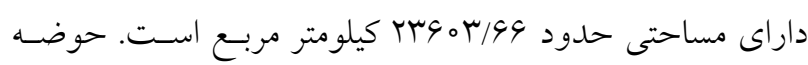

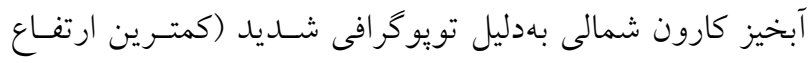
متر و بيشترين ارتفاع VVI

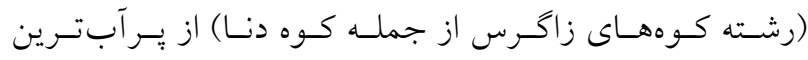

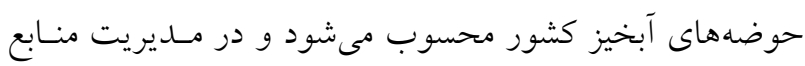

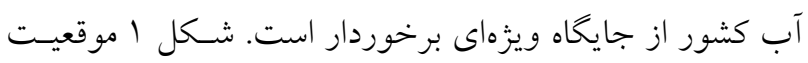

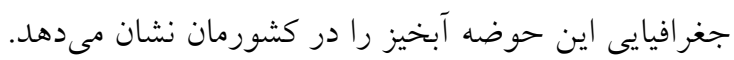

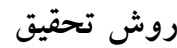

بهمنظور شبيهسازى فرايند بارش - رواناب دادههاى بارش و دبى كي

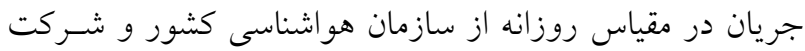

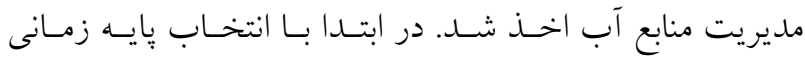

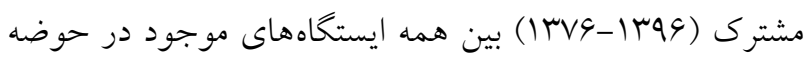

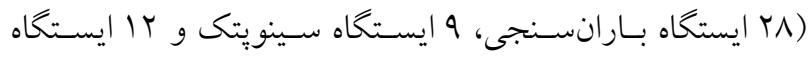

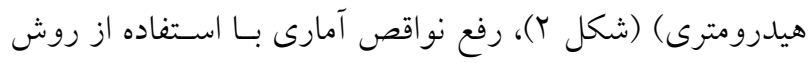

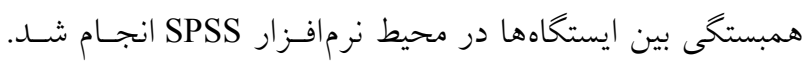

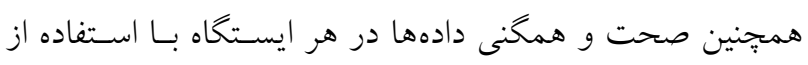




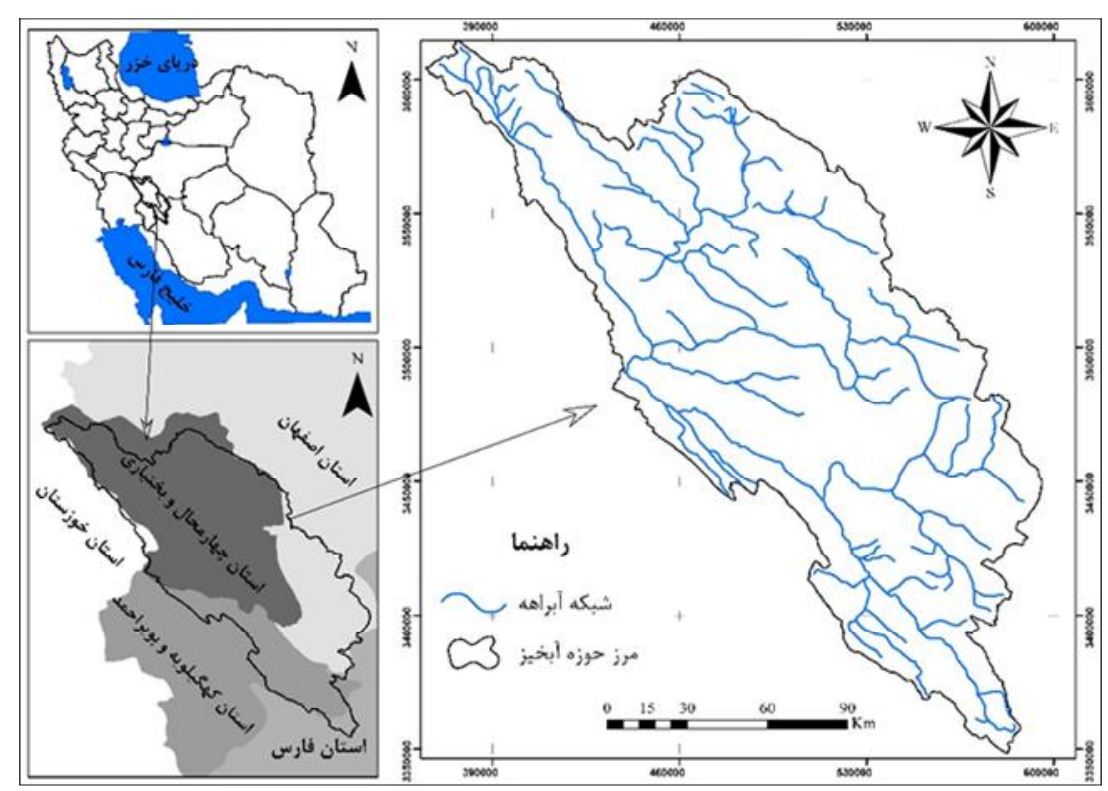

شكل 1. موقعيت جغرافيايى حوضه آبخيز كارون شمالى در كشور

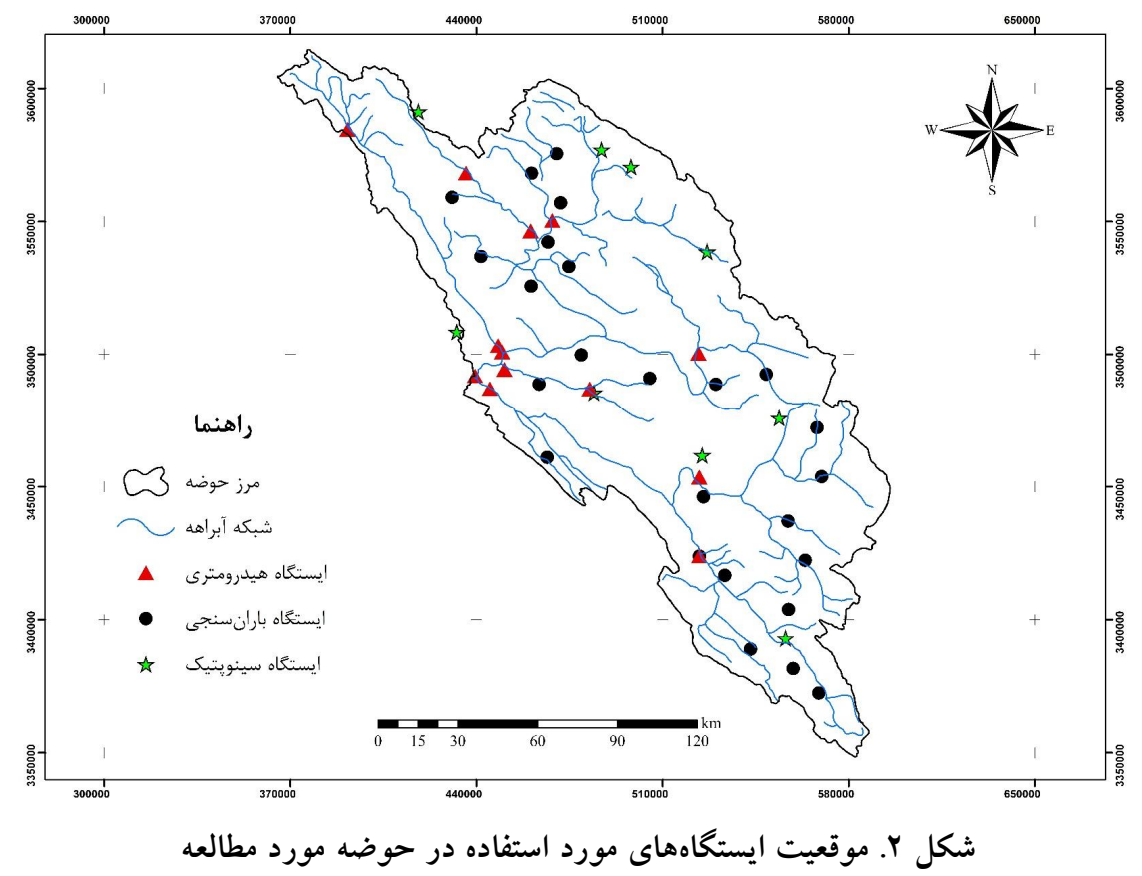

$\Sigma_{\mathrm{m}}=\frac{1}{\mathrm{~m}} \sum_{\mathrm{i}}^{\mathrm{m}}\left|\mathrm{x}_{\mathrm{N}[\mathrm{i}, \mathrm{k}]}-\mathrm{y}_{\mathrm{i}}\right|^{2} \quad 1 \leq \mathrm{k} \leq \mathrm{p}$

تابع مربوطه كاما براى هر خروجى yi متناظر با بردار ورودى در

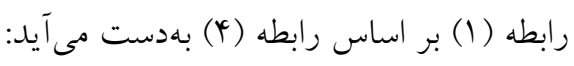

$\mathrm{Y}_{\mathrm{M}}=\frac{1}{2 \mathrm{M}} \sum_{\mathrm{I}}^{\mathrm{M}}\left|\mathrm{y}_{\mathrm{N}[\mathrm{i}, \mathrm{k}]}-\mathrm{y}_{\mathrm{i}}\right|^{2} \quad 1 \leq \mathrm{k} \leq \mathrm{p}$

(
نشان داده شده با رابطه r به مــلى همــوار بـا مشـتقات جزئسى مرتبه اول محدود شد. آماره كاما (Г) واريانس بخشى از دادههـا را كه تابع f قادر به توجيه آن نيست نشان مىدهد. مقــار Г بـر

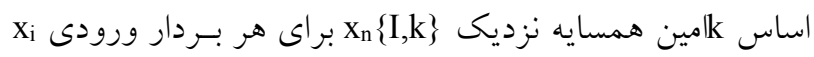

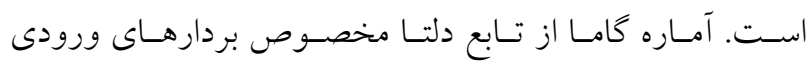
بهورت رابطه (r) بهدست مى آيد: 


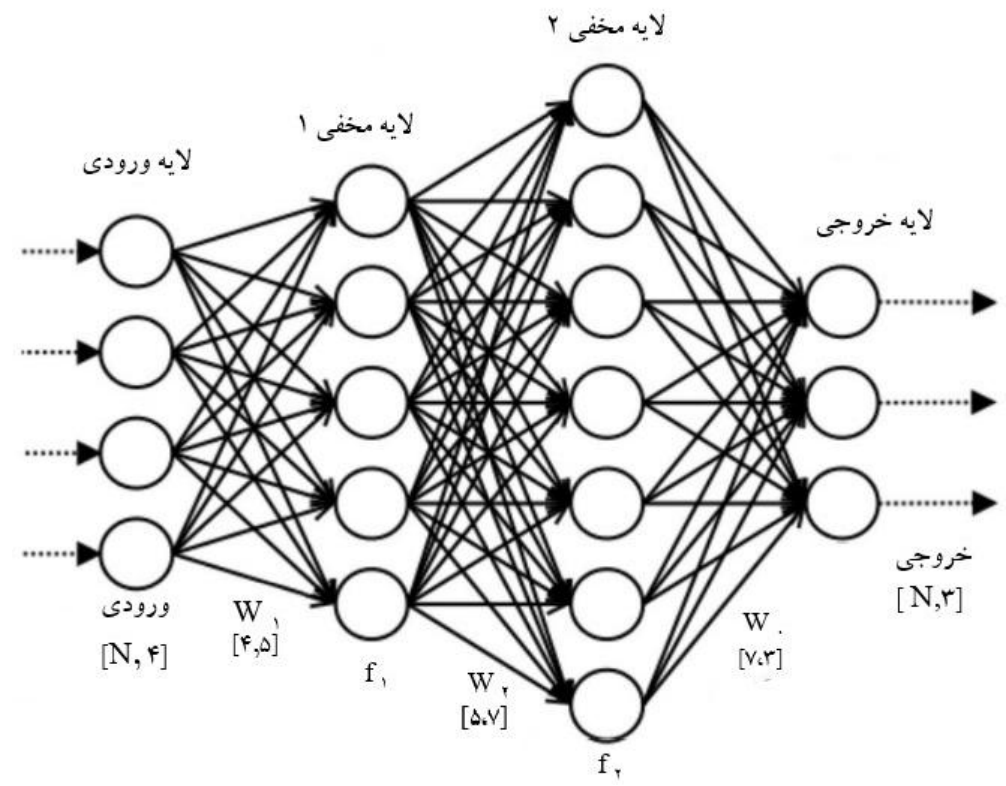

شكل r. ساختار شبكه عصبى مصنوعى

استفاده از آزمون M مىتوان تعداد دادههاى مـورد نيـاز را بـراى

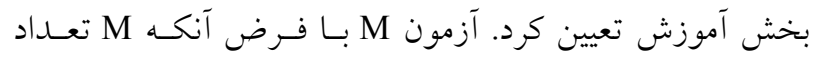

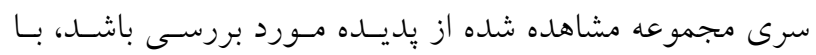

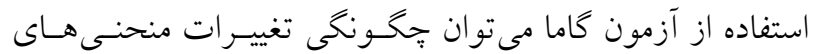

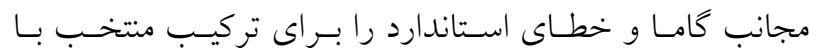

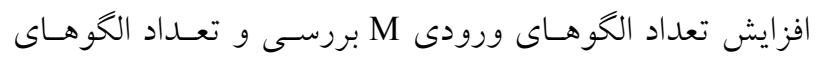
ورودى كه مقدار اين آمارهها را به حالت پايدار براى ايجاد مدل

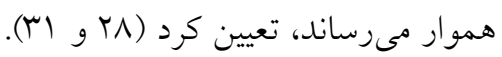

شبكه عصبى مصنوعى(ANN) ( )

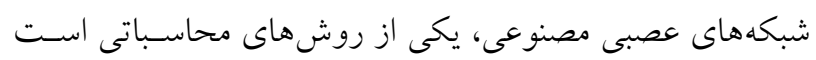

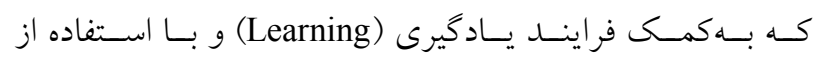
يردازشخرهايى بنام نرون تلاش مى كند با شناخت روابط ذاتى

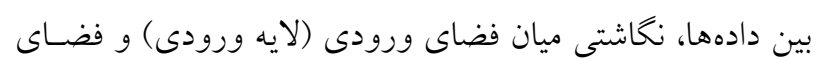
مطلوب (لايه خروجى) ارائه دهد. هر شبكه عصبى مصسنوعى از

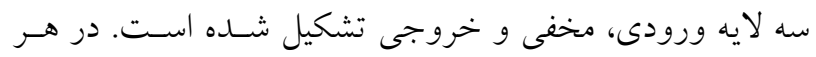

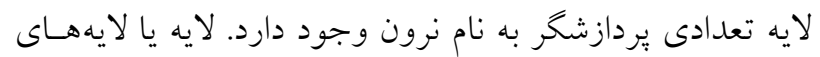

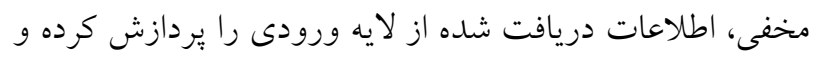
در اختيار لايه خروجى قرار مىدهند (شكل بَ).
كه مقدار y معين براى لمين همسـايه نزديــ بـردار ورودى Xi در رابطه (1) است. ميزان p را مى توان بين •ه-ه إنتخاب كرد (11 و 1). با ايجاد رابطه رگرسيونى خطى رابطـه زيــر حاصـل

$\mathrm{Y}=\mathrm{A} \sigma+\Gamma$

وقتى Oبهمت صفر ميل كند مقدار آماره كاما بهصـورت زيـر

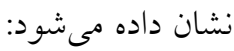

$\mathrm{Y}_{\mathrm{M}} \rightarrow \operatorname{VAR}(\mathrm{r}) \sigma_{\mathrm{M}} \rightarrow 0$

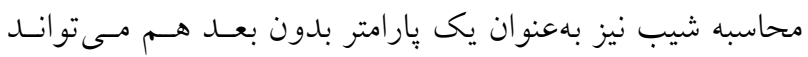

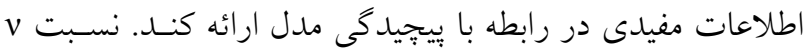

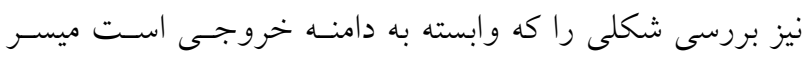

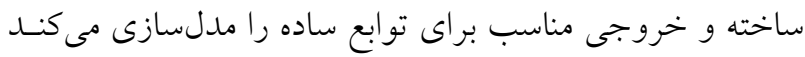
كه بهصورت رابطه (V) محاسبه مىشود: $\mathrm{V}_{\text {ratio }}=\frac{\Gamma}{\operatorname{VAR}(\mathrm{Y})}$ واريانس خروجى را نشان مسيدهــ. ايـن نسـبت بــه VAR(Y) صورت نرمال بين ا-ه تغيير مى كند كه هرجه ميزان آن به صفر

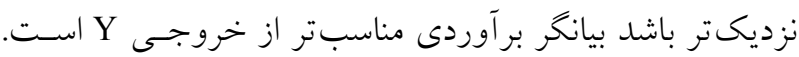

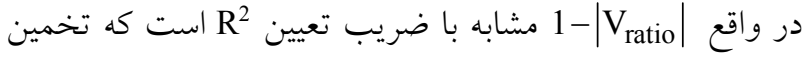

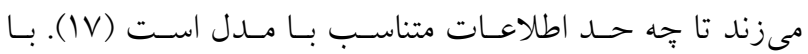




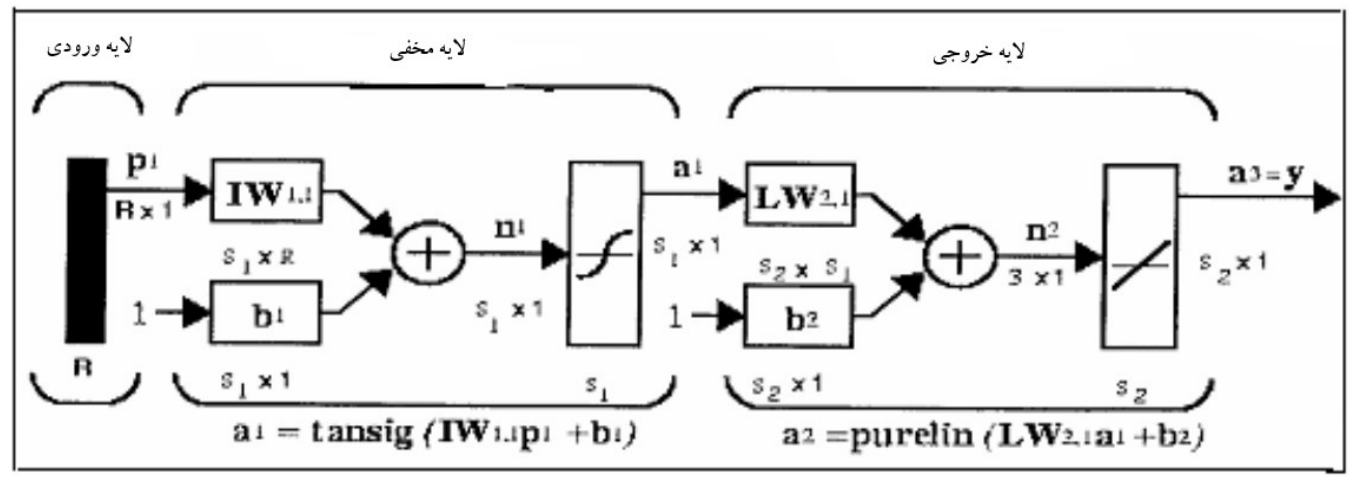

شكل ץ. تصوير نمادين از شبكههاى برسبترون جندلايه (MLP)

است. متداولترين الكوريتم (Bounded Activation Function)

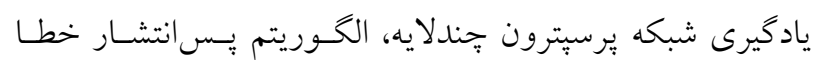
اسـت كـهـ در 9 درصســ مطالعـات (Back Propagetion) هيدرولوزى مورد استفاده قرار مى گيرد (r و 19).

ماشين بردار يشتيبان (SVM) الكوريتم ماشين بردار يشتيبان كه توسط وإِينـى (1990) ارائسه. شده، بر اساس نظريه ابعادى و تئورى يادگيرى آمارى بنـا شــهـ

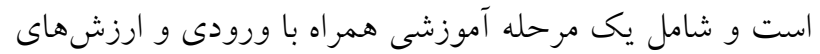
اهداف خروجى است. بر اساس ايسن نظريـه يـادكيرى آمـارى،

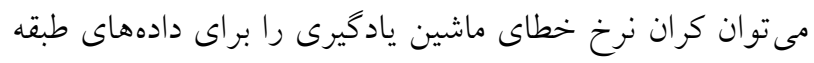

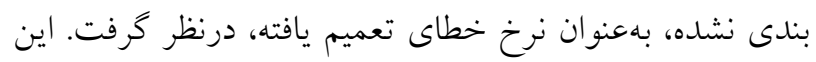

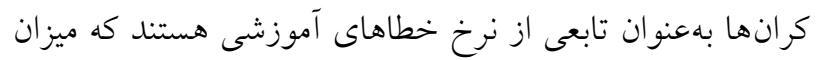

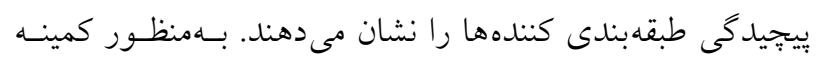

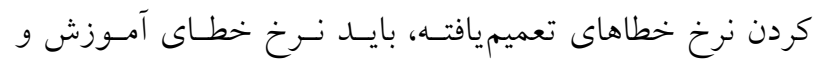

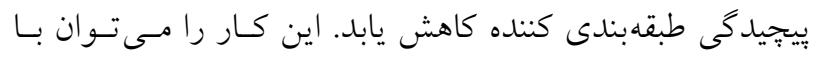

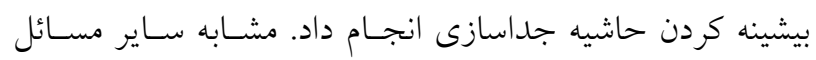

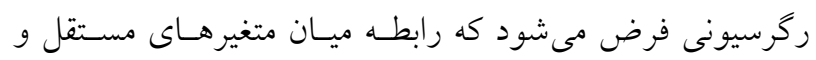

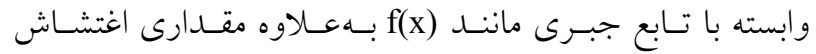
(خطاى مجاز ( ع )) مشخص مىشود.

$\mathrm{f}(\mathrm{x})=\mathrm{W}^{\mathrm{T}} . \varnothing(\mathrm{x})+\mathrm{b}$

$y=f(x)+$ noise

جنانجـه W (بـردار ضـرايب) و b (ثابـت) مشخصـهــاى تـابع
شـبكه عصسبى مصــوعى يكسى از دسـتاوردهايى اسـت كـه بـاــا

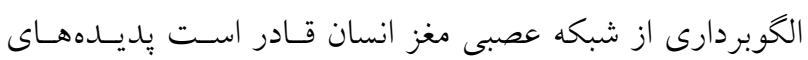

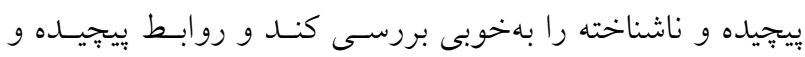

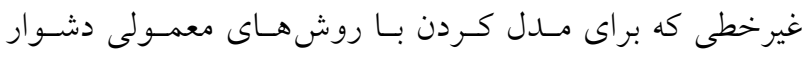

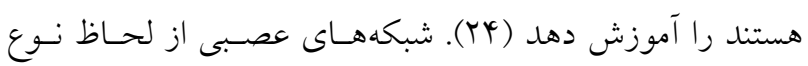

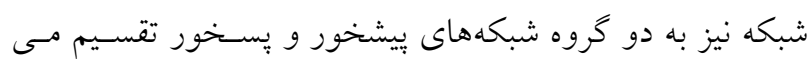

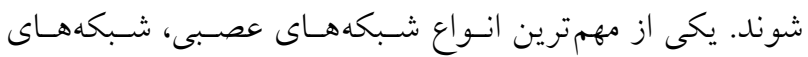
يرسيترون خند لايه (MLP) است. ايـن شبكهها از جندين لايسه

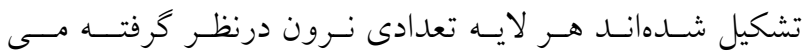
شـود كـه بـهـوسـيله اتصالاتى به نـرونهـاى لايـهــاى مجـاور

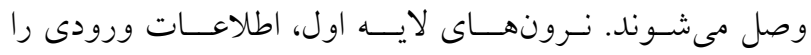

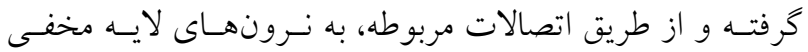

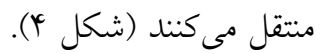

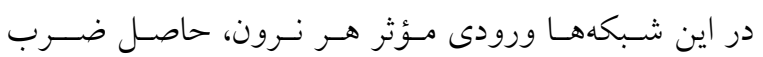
خروجى نرونهاى لايه قبل در وزنهاى ميان آن نرونها است. Net $_{p i}=\sum \mathrm{W}_{\mathrm{ij}} \mathrm{a}_{\mathrm{pi}}+\mathrm{b}_{\mathrm{i}}$ در اين رابطه، a مقدار خروجى لايه قبلى و W وزنهاى لايسه

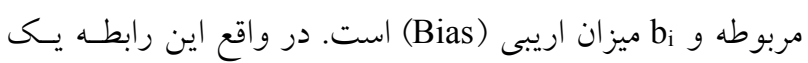

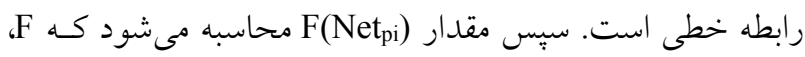

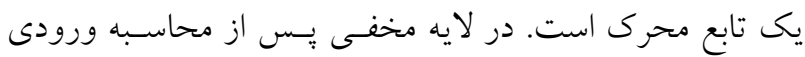

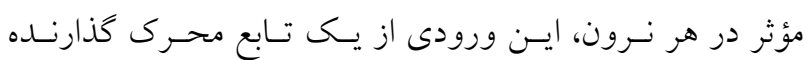

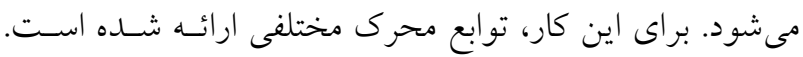

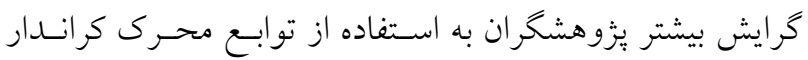


سناريوى سوم: فقط دادههاى رواناب درنظر گرفته شدند تـا دادهاى روزهاى بعدى دبى بر اساس آمار روزهاى قبـل و روز جارى يسيش بينسى شـوند. رابطـهـ ايسن سـناريو را نيـز مسى تـوان بهصورت زير درنظر كرفت:

$\mathrm{Q}_{\mathrm{t}+1}=\mathrm{f}\left(\mathrm{Q}_{\mathrm{t}-1}, \mathrm{Q}_{\mathrm{t}-2}, \mathrm{Q}_{\mathrm{t}-3},\right)$

براى افزايش كارايى هر دو مدل، همه دادهها در محيط نرمافـزار MATLAB بيشبينى شده و ارزيابى كارايى مدلها از شـاخصهـاى آمـارى

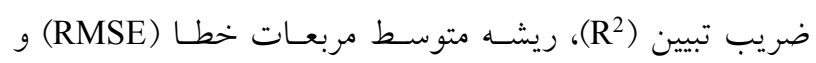

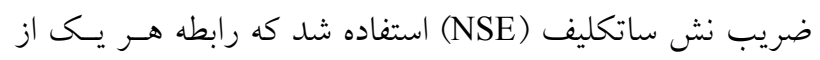
شاخص هاى مذكور در زير آمده است.

$$
\mathrm{R}^{2}=\left[\frac{\sum_{\mathrm{N}}^{\mathrm{i}=1}\left(\mathrm{x}_{\mathrm{i}}-\overline{\mathrm{x}}\right)\left(\mathrm{y}_{\mathrm{i}}-\overline{\mathrm{y}}\right)}{\sqrt{\sum_{\mathrm{N}}^{\mathrm{i}=1}\left(\mathrm{x}_{\mathrm{i}}-\overline{\mathrm{x}}\right)^{2} \cdot \sum_{\mathrm{N}}^{\mathrm{i}=1}\left(\mathrm{y}_{i}-\overline{\mathrm{y}}\right)^{2}}}\right]^{2}
$$

RMSE $=\sqrt{\frac{\sum_{\mathrm{i}=1}^{\mathrm{N}}\left(\mathrm{x}_{\mathrm{i}}-\mathrm{y}_{\mathrm{i}}\right)^{2}}{\mathrm{~N}}}$

$\mathrm{NSE}=1-\frac{\sum_{\mathrm{N}}^{\mathrm{i}=1}\left(\mathrm{x}_{\mathrm{i}}-\mathrm{y}_{\mathrm{i}}\right)^{2}}{\sum_{\mathrm{N}}^{\mathrm{i}=1}\left(\mathrm{x}_{\mathrm{i}}-\overline{\mathrm{x}}\right)^{2}}$

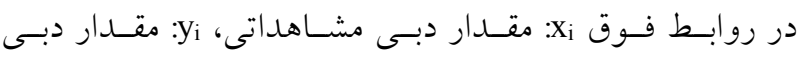

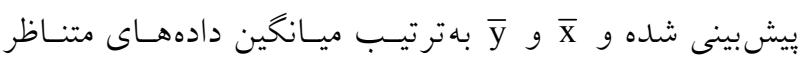
است. مدلى داراى بهترين نتيجـهـ اسـت كـه ضـريب تبيـين و ضريب ناش ساتكليف نزديك بـه يـك و RMSE نزديـى بـه صفر داشته باشد.

\section{نتايج و بحث}

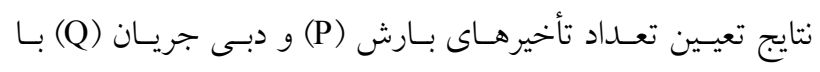

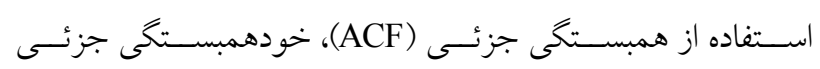
R Studio و همبستخى متقاطع (PACF)

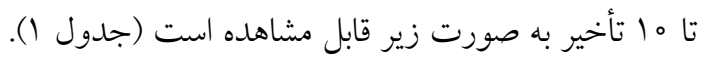

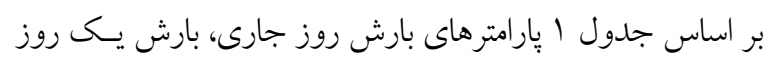

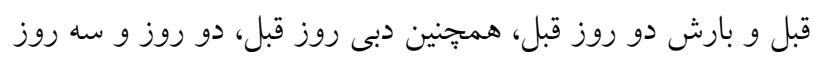

ركرسيونى و ل اليز تابع كرنل باشد، آنكاه هدف بيدا كردن فـرم

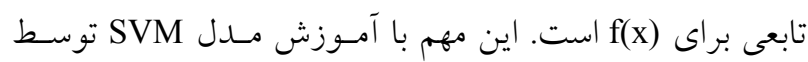

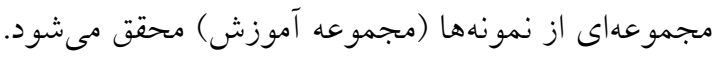

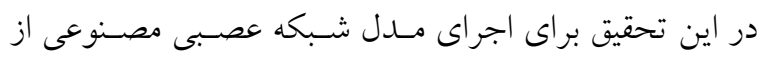

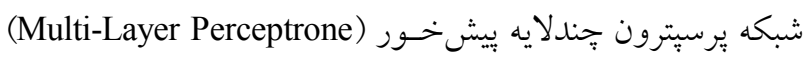

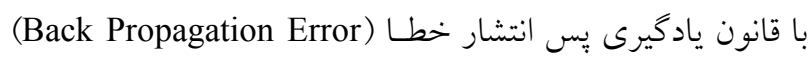

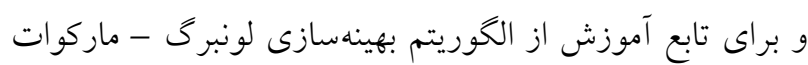

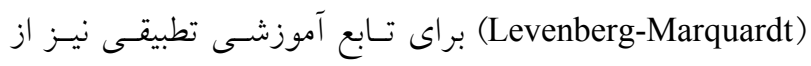

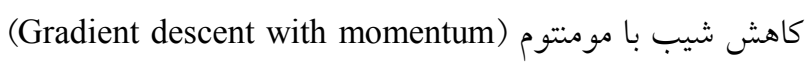

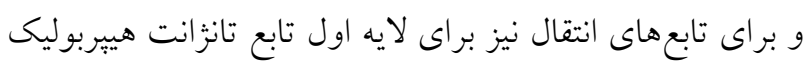

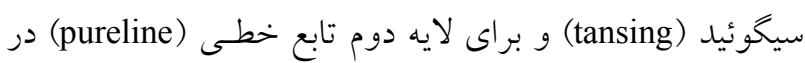
محيط نرمافزار MATLAB R2018b استفاده شد. در اين تحقيق

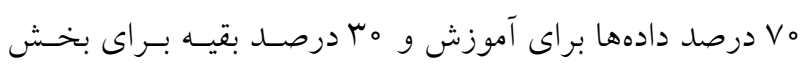

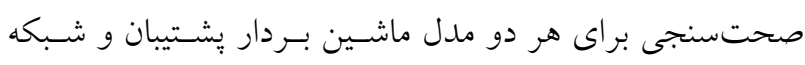

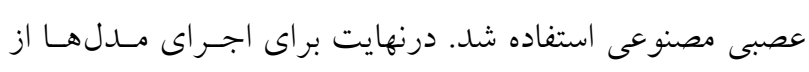

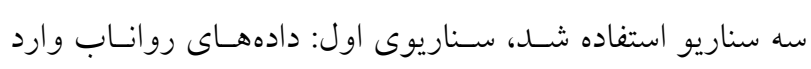

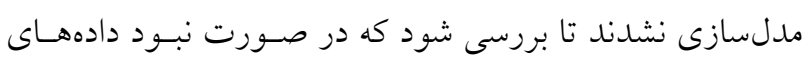

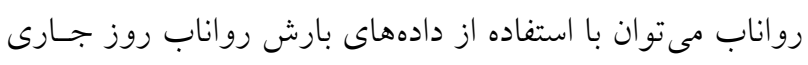
را ييشبينى كرد كه مىتوان بهصورت رابطه زير، آن را بيان كرد: $Q_{t}=f\left(P_{t}, P_{t-1}\right)$

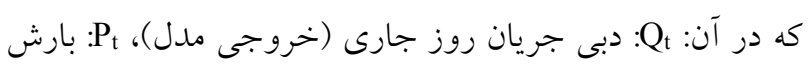

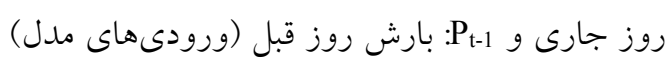

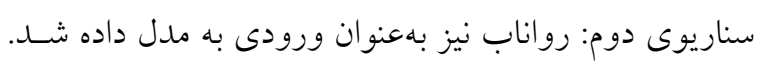

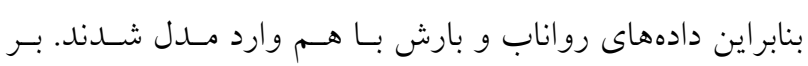

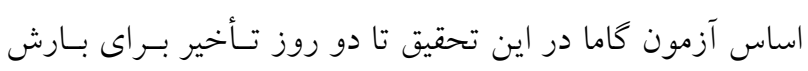

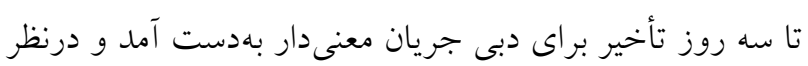

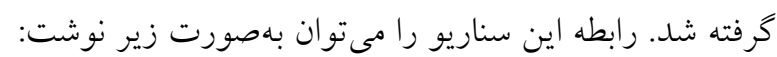
$\mathrm{Q}_{\mathrm{t}}=\mathrm{f}\left(\mathrm{P}_{\mathrm{t}}, \mathrm{P}_{\mathrm{t}-1}, \mathrm{P}_{\mathrm{t}-2}, \mathrm{Q}_{\mathrm{t}-1}, \mathrm{Q}_{\mathrm{t}-2}, \mathrm{Q}_{\mathrm{t}-3}\right)$

كه در آن: Q : دبى جريان روز جارى (خروجى مدل)،

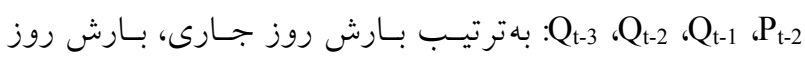

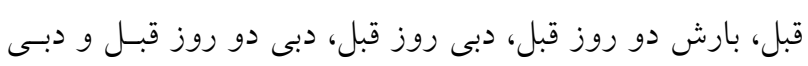

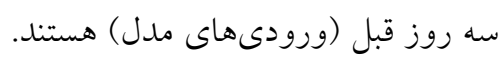


جدول ا. نتايج تعيين تأخيرهاى بارش و دبى جريان در حوضه آبخيز مورد مطالعه

\begin{tabular}{|c|c|c|c|c|c|c|c|c|c|c|c|}
\hline $\mathrm{t}-10$ & $\mathrm{t}-9$ & $\mathrm{t}-8$ & $\mathrm{t}-7$ & $\mathrm{t}-6$ & $\mathrm{t}-5$ & $\mathrm{t}-4$ & $t-3$ & $\mathrm{t}-2$ & $\mathrm{t}-1$ & \multirow[b]{2}{*}{$(\mathrm{P})$} & \multirow{3}{*}{$(\mathrm{ACF})$} \\
\hline $0 / 1 \mu_{0} *$ & $\circ / 1 \circ q^{*}$ & $\circ / 1 \circ Q^{*}$ & $0 / 110^{\circ *}$ & $0 / 104 *$ & $0 / 111 \%$ & $0 /|Y|^{*}$ &.$/ 110^{*}$ & $\circ / 19 Y^{*}$ & o/4ra* & & \\
\hline$\circ / 000 \%$ & $\circ /\left.00\right|^{*}$ & $\circ / \circ \Delta r^{* *}$ & $\circ / \circ \Delta r^{* *}$ & $\circ / \circ \Delta \Delta^{*}$ & $\circ / 0 \Delta \varphi^{*}$ & $\circ / \circ \Delta \Lambda^{*}$ & $0 / 091 \%$ & $\circ / \circ V Y^{*}$ & $\circ / \circ V Q^{*}$ & (Q) & \\
\hline $0 / 09 Y^{*}$ & $0 / 04 \Delta^{n s}$ & 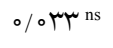 & $0 / 04 q^{\mathrm{ns}}$ & $0 \%$ krns & $\circ / r^{n} \mathrm{~ns}$ & $0 / 091 *$ & \%०V०* & $-0 / 0 \mu_{Y}$ & ०/4ra* & $(\mathrm{P})$ & \multirow{2}{*}{ (PACF) } \\
\hline$\circ / r_{0}$ ns & o/orns & $0 / \%$ rys & \% & $0 \% q^{\text {ns }}$ & $0 / 0 y^{n}$ ns & o/ pre ns & $\circ / \circ \Delta 1^{*}$ & $0 / 099^{*}$ & $\circ / \circ V Q^{*}$ & (Q) & \\
\hline$\% / 01 \wedge^{n s}$ & $\% / 01 \wedge^{\mathrm{ns}}$ & $\circ / \% Y^{\circ}{ }^{n s}$ & $\circ / \circ \Delta \varphi^{* *}$ & $\% \% Q^{\mathrm{ns}}$ & $\circ / 0 Y I^{\mathrm{ns}}$ & \%/ YY ns & $\circ / \circ Y V^{n s}$ & $\circ / 0 Y \wedge$ ns & $0 / 0$ pr ns & - & \multirow{2}{*}{ (CCF) } \\
\hline $0 / 049^{*}$ & $\circ / 0 \Delta \Gamma^{* *}$ & $\circ / \circ \Delta Y^{*}$ & $0 / 091 *$ & $\circ / \circ \Delta Y^{*}$ & $0 / 094 *$ & $\circ / \circ \vee q^{*}$ & O/KY" & $\circ / \backslash Q V^{*}$ & $\circ / 1 \Lambda^{* *}$ & - & \\
\hline
\end{tabular}

جدول r. انتخاب پارامترهاى مؤثر در مدلسازى بر اساس GT براى زيرحوضهها

\begin{tabular}{|c|c|c|c|c|c|c|}
\hline نسبت V & خطاى استاندارد & شيب & ضريب كاما & ماسك & تركيب & نام حوضه \\
\hline$r / \Lambda 1 \circ r$ & $\circ / 04 \circ 940$ & -o/AYVOV & -/9DTDG & .11111111 & $\mathrm{P}$ & \\
\hline r/DQIV & - ITQTV & $1 / 4019$ & -/AqVqY & 101111111 & Pt-1 & \\
\hline $1 / 9910$ & \% VqVRY & -O/YYYMI & OMYTMA & 111110111 & Qt-1 & كارون شمالى \\
\hline OTVGM & - ovqAkA & DTMTGY & $0 / 099719$ & 111111011 & Qt-2 & \\
\hline o/quvir & $\circ / 1 M^{\circ} \circ \mathrm{V}$ & \%оOrTara & OTMYYA & 111111110 & Qt-4 & \\
\hline
\end{tabular}

جدول r. انتخاب تركيب مناسب در مدلسازى بر اساس GT

\begin{tabular}{|c|c|c|c|c|c|c|}
\hline نسبت V & خطاى استاندارد & شيب & ضريب كاما & ماسك & متغيرهاى تركيبى & نام حوضه \\
\hline$-V / D F Y q$ & OMITTG & $9 / V 9 \wedge 9$ & $-1 / M \wedge \Delta V$ & 100001000 & Pt, Qt-1 & \multirow{2}{*}{ كارون شمالى } \\
\hline$-9 / \pi \Delta \cdot 1$ &.$/ 09004$ & r/gkpt & $-1 / 0 \wedge \vee \Delta$ & 110001110 & Pt, Pt-1, Qt-1, Qt-2, Qt-3 & \\
\hline
\end{tabular}

كرفته شد. درنهايت با اسـتفاده از آزمـون گامـا بـارامترىهـايى كـهـ داراى بيشترين ميزان آماره گاما بودند بهعنوان بـارامتر ورودى بهينــه

انتخاب شدند (جدول r ).

بر اساس جدول بارش روز جارى، بـارش يـك روز قبـل

داراى تأثير بسزايى در خروجى هستند، همجنين دبى روز قبل و دو روز قبل داراى بيشترين تأثير در دبى خروجى حوضه هستند (بهدليل تعيين تركيبهاى زياد و در كل تأثير كم جريـان جهـار

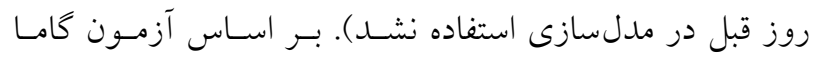
بهترين تركيب كه داراى كمترين مقــار آمـاره كامـا و كمتـرين مقدار خطاى استاندارد بود مشخص شد (جدول r). مدلهاى شبكه عصبى مصنوعى و ماشين بردار يشـتيبان بـر
قبل بلهنوان مهمترين پِارامترهـا در تعيـين تركيـب و ورودى مــل انتخاب مىشوند. اين نتيجه بيانگر اين اسـت كـه بـارش بيشـتر در حوضه بهصورت اثر بر اشباع شدكى، كـاهش نفوذيـذيرى خـاك و

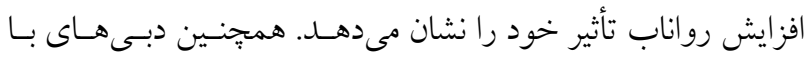
تأخير سه روزه نشاندهنده اهميت بالاى دبى بايه و همجنــين زمـان تمركز حوضه است. همبستكى متقابل بارش و دبسى از تـأخير يـنج روزه به بعد درصد سطح معنى دارى كمتر ديــده مسىشـود. بـهدليـل حجم بالاى محاسبات و دادهها بـراى انتخـاب يار امترهـاى بهينـه و مدل مناسب از ضـرايب خودهمبسـتكى، خودهمبسـتخى جزئسى و همبستخى متقاطع تا ها روز تأخير براى بارش و دبى جريان اسـتفاده شد. در مجموع براى تعيين تركيب ورودى بهينـه 9 يـارامتر درنظـر 
و ابزارى مناسب بــراى مطالعـه فراينـدهاى هيـدرولوزيكى و

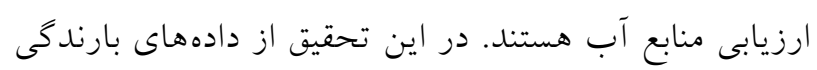
و دبى جريان براى شبيه سازى فرايند بارش-رواناب استفاده

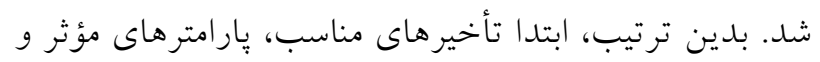

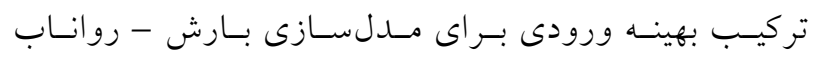

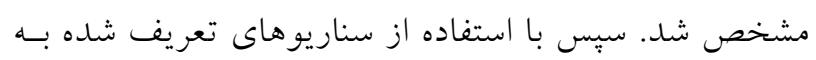
مدل سازى با استفاده از دو مدل هوش مصنوعى شامل ANN

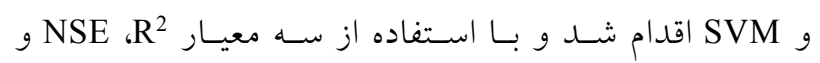

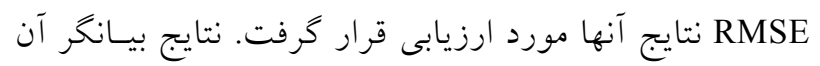

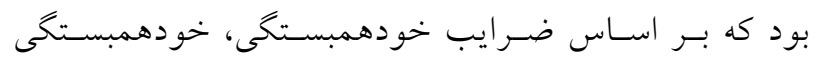

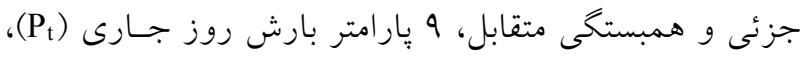

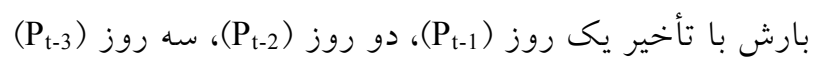

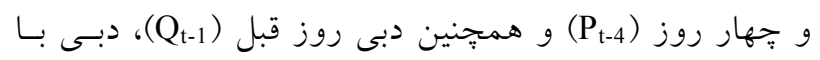

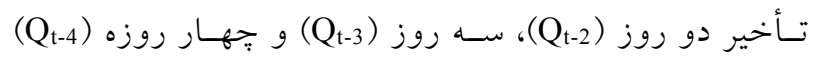

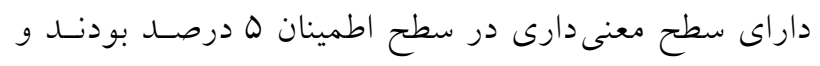

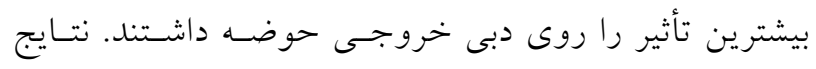

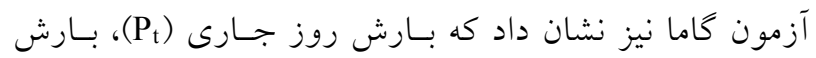

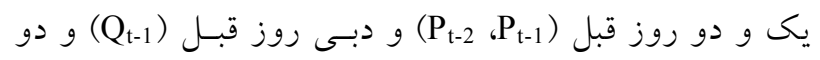

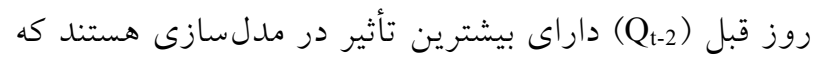

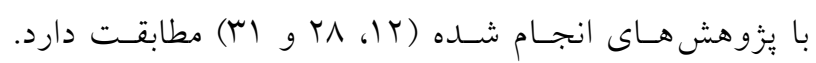

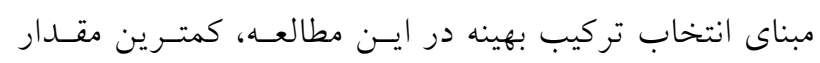

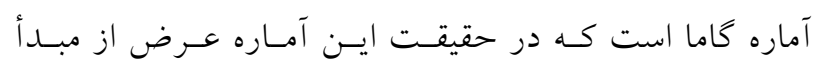

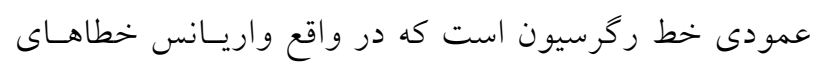

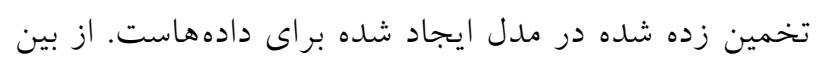

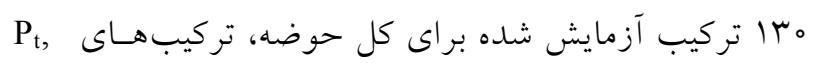
مناسـب تـرين تركيـب بـراى P

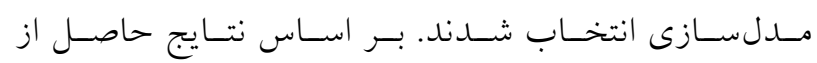

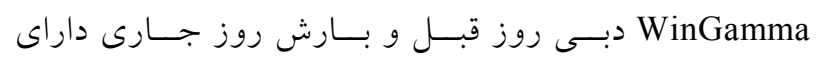

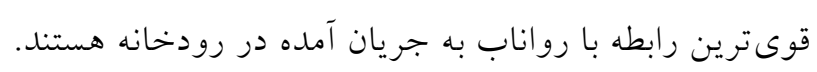

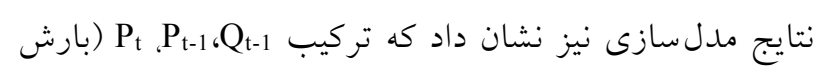

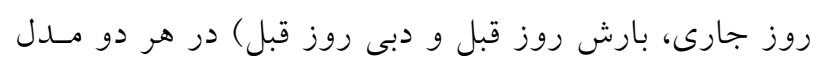

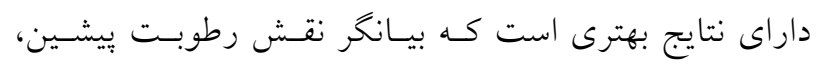

MATLAB اساس سه سناريوى تعريف شده در محيط نرم|فزار

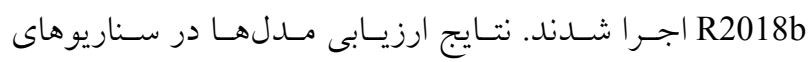

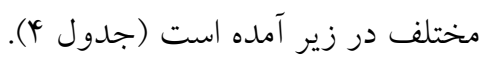

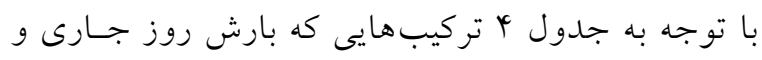

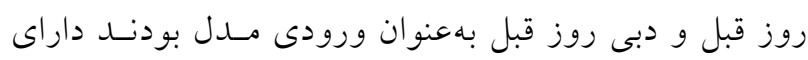

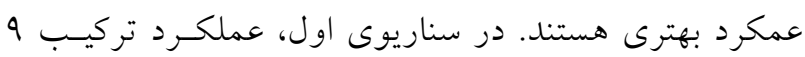

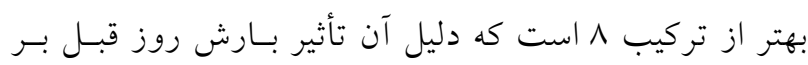

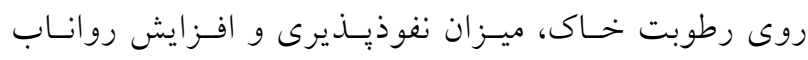

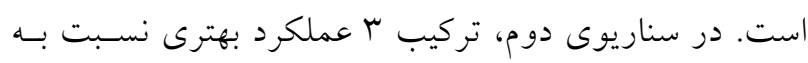

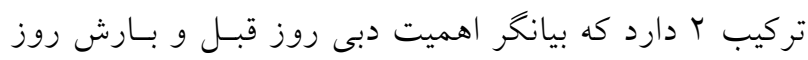

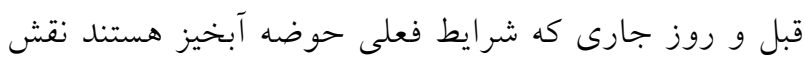
مهمى در توليد رواناب دارند. در سناريوى سوم نيز عملكرد

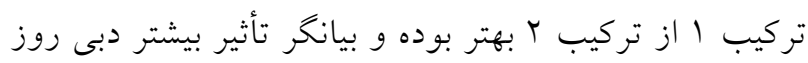

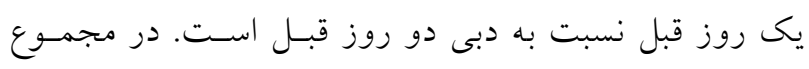

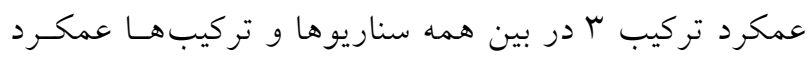
بهترى داشته است (شكل ه ه).

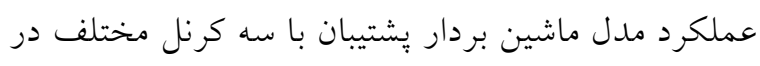
مرحله آموزش و صحتسنجى در جدول هـ مشاهده مى شود.

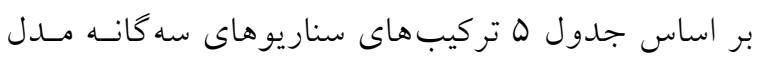

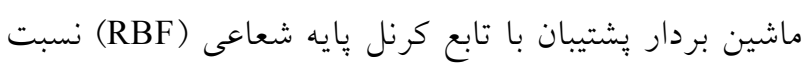

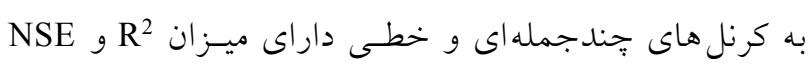

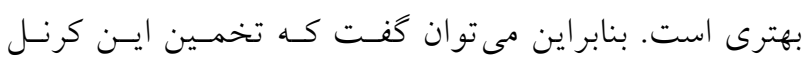

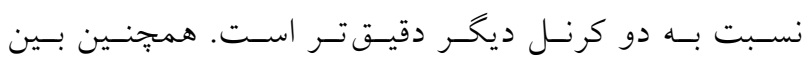

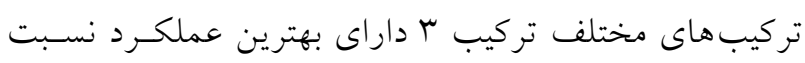

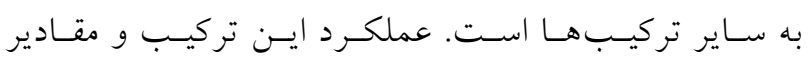
شبيهسازى رواناب در شكل 9 قابل ملاحظه است.

\section{نتيجه گيرى}

استفاده از روش هاى نوين هـوش مصــوعى در شـبيهسـازى

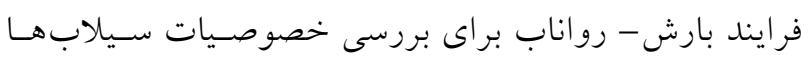

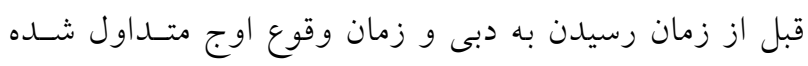

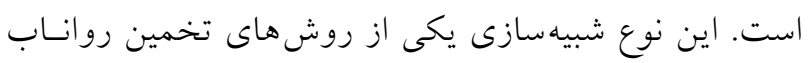


جدول f. نتايج ارزيابى مدل شبكه عصبى مصنوعى در سناريوهاى مختلف شبيهسازى رواناب

\begin{tabular}{|c|c|c|c|c|c|c|c|c|c|}
\hline \multicolumn{3}{|c|}{ صحتسنجى } & \multicolumn{3}{|c|}{ آموزش } & \multirow{2}{*}{ يار امترهاى ورودى } & \multirow{2}{*}{ تعداد } & \multirow{2}{*}{ تعداد نرو } & \multirow{2}{*}{ تركيب } \\
\hline RMSE & NSE & $\mathrm{R}^{2}$ & RMSE & NSE & $\mathrm{R}^{2}$ & & & & \\
\hline $0 / 0114$ & $\circ N Y$ & o/Ar &.$/ 01$ KO & $\circ / \mathrm{NA}$ & $\circ / \wedge Q$ & Qt-1 & r & 14 & 1 \\
\hline $0 / 0|r|$ & $\circ / \mathrm{V}$ & $\circ / \wedge 9$ & .10110 & $\circ / \wedge 1$ & $\circ / M$ & Pt ،Qt-1 & 14 & 10 & r \\
\hline$\circ / 01 \circ 0$ & O/AT & $\circ / 19$ & $0 / 010 Y$ & $\circ / \wedge$ & $\circ / \wedge 9$ & Pt ،Pt-1،Qt-1 & 14 & ir & r \\
\hline $0 / 194$ & $0 / 90$ & $0 / 99$ &.$/ T \mathrm{TQ}$ & $\circ / \vee \circ$ & $\circ / Y^{4}$ & Qt-1 ،Qt-2 & ir & 10 & i \\
\hline ०/OYI & $0 / 9 \mu$ & $\circ / V_{0}$ & $0 / Y 19$ & $0 / 99$ & $\circ / V Y$ & Qt-1،Qt-2 ،Qt-3 & Tr & ro & 0 \\
\hline $0 / 0 / k T$ & $\circ / \mathrm{VV}$ & o/AY & $0 / 0114$ & $\circ / \wedge \circ$ & o/AV & Pt ،Pt-1،Qt-1 ،Qt-2 & YY & ir & 9 \\
\hline.$/ 410$ & $0 / 94$ &.$/ 90$ &.$/ 9 \wedge 4$ &.$/ 90$ & $0 / 99$ & Pt ،Pt-1 Pt-2،Qt-1،Qt-2 & 10 & $\checkmark$ & V \\
\hline$\circ / V \circ D$ & $0 / 49$ & .01 & O/TOQ & $\circ / 4 \wedge$ & o/QY & $\mathrm{Pt}$ & Ir & IT & $\wedge$ \\
\hline$. / N \mid t$ & $0 / 49$ & $\circ / \Delta r$ & $\circ / 0 \circ Y$ & $\circ / 01$ & $\circ / 09$ & Pt ،Pt-1 & ir & 10 & 9 \\
\hline$\circ / V_{0} 1$ & $\circ / 0 \circ$ & $\circ / 00$ & $\circ / \Upsilon \wedge 0$ & $\circ / \Delta r$ &.$/ 09$ & Pt ،Pt-1 Pt-2،Qt-1،Qt-2 ،Qt-3 & ro & IV & 10 \\
\hline
\end{tabular}

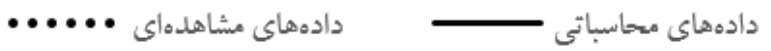

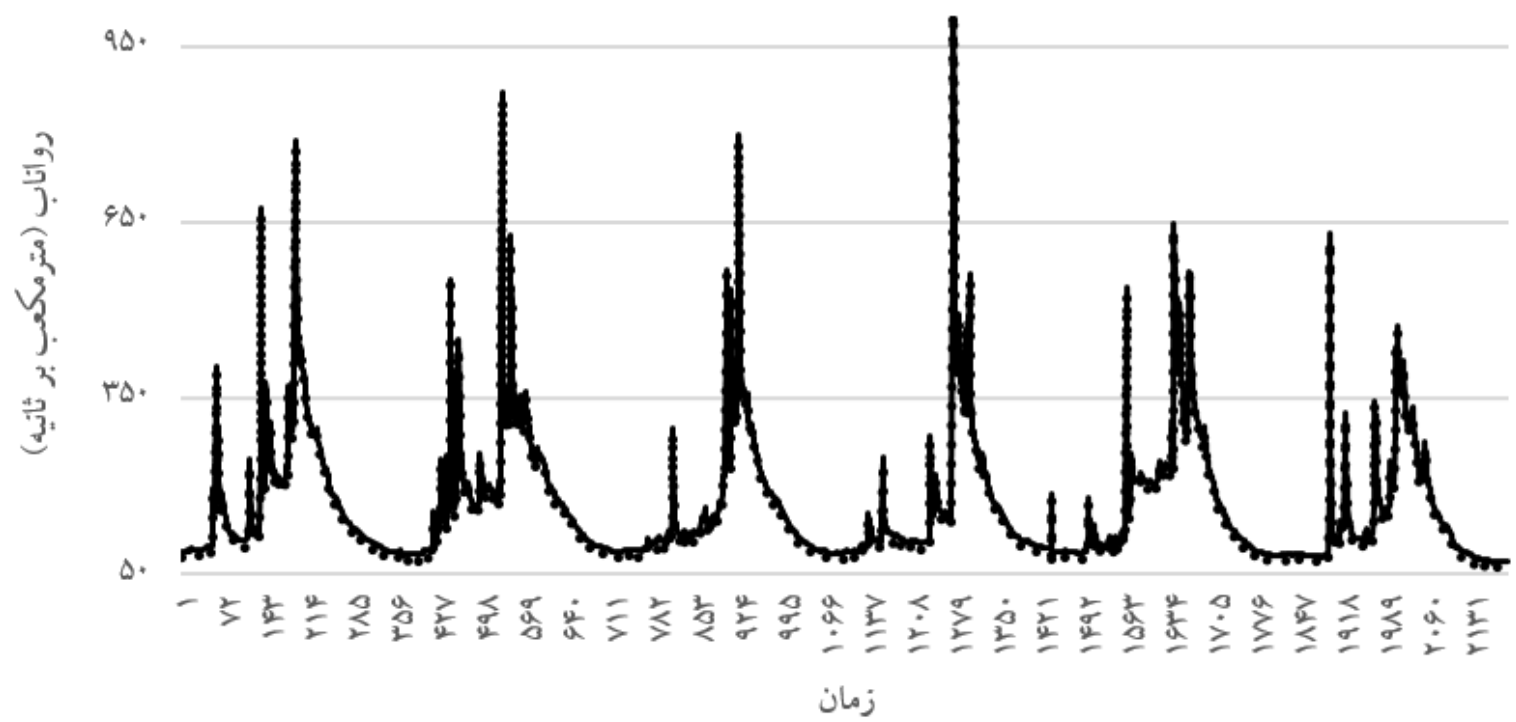

شكل ه. مقادير مشاهداتى و محاسباتى ميزان رواناب در حوضه آبخيز كارون شمالى با بهترين تركيب شبكه عصبى مصنوعى 
جدول ه. نتايج ارزيابى كرنل هاى مختلف مدل ماشين بردار بشتيبان در سناريوهاى مختلف شبيهسازى بارش - رواناب

\begin{tabular}{|c|c|c|c|c|c|c|c|}
\hline \multicolumn{3}{|c|}{ صحتسنجى } & \multicolumn{3}{|c|}{ آموزش } & \multirow{2}{*}{ كرنل } & \multirow{2}{*}{ تركيب } \\
\hline RMSE & NSE & $\mathrm{R}^{2}$ & RMSE & NSE & $\mathrm{R}^{2}$ & & \\
\hline$\circ / 1 \circ \wedge$ & $\circ / \mathcal{C}_{0}$ & $0 / 4 q$ & $\circ / 1 \circ Y$ & $\circ / D F$ & $\circ / Q \mu$ & $\mathrm{RBF}$ & \multirow{3}{*}{1} \\
\hline $0 / 91 Y$ & $0 / N G$ & $\circ / \Lambda$ & $\circ / D \circ r$ & $0 / 41$ & $\circ / \mu_{0}$ & جند جملهاى & \\
\hline $0 / 901$ & $\circ / Y V$ & $0 / \pi q$ & $0 / 490$ & $0 / 4 q$ & $0 / 41$ & خطى & \\
\hline$\circ / Y \circ D$ & $\circ / V_{0}$ & $\circ / V^{4}$ & $0 / 1 Y Y$ & $\circ / N$ & $\circ / V \wedge$ & $\mathrm{RBF}$ & \multirow{3}{*}{ r } \\
\hline $0 / Y \mu \wedge$ & $\circ / \mathrm{V} 0$ & $\circ / N Q$ & O/YA & $0 / 9 \mathrm{~V}$ & $\circ / V_{1}$ & جند جملهاى & \\
\hline $0 /$ TGK & $0 / 9 \wedge$ & $0 / 99$ & ./TL & $0 / 91$ & $0 / 90$ & خطى & \\
\hline$\circ / 1 \circ \wedge$ & $\circ / v 9$ & $\circ / \Lambda Y$ & .091 & $\circ / \mathrm{VA}$ & $\circ / \Lambda 1$ & $\mathrm{RBF}$ & \multirow{3}{*}{$r$} \\
\hline $0 / 119$ & ०/VG & ०NG & .099 & $\circ / N$ & $\circ / V Q$ & جند جملهاى & \\
\hline - /TO & $0 / 99$ & $0 / 90$ & $\circ / 1 \circ 0$ & $0 / 94$ & $0 / 9 T$ & خطى & \\
\hline $0 / 119$ & $\circ / 4 Q$ & $0 / 4 q$ & $\circ / 1 Y 0$ & $0 / 49$ & $\circ / 01$ & $\mathrm{RBF}$ & \multirow{3}{*}{ 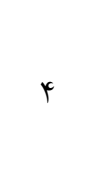 } \\
\hline$\circ / 19 \circ$ & $0 /$ M & $0 / 49$ & $0 / 1 M y$ & $0 / 49$ & $0 / 49$ & جند جملهاى & \\
\hline $0 / Y 01$ & $0 / \mu q$ & $0 / 41$ &.$/ 109$ & o/4r & $0 / 4 y$ & خطى & \\
\hline $0 / 149$ & $\circ / N \Delta$ & $0 / 49$ & $0 / 119$ & $\circ / \mu V$ & $0 / 49$ & $\mathrm{RBF}$ & \multirow{3}{*}{0} \\
\hline o/lro & $\circ / \mu Y$ & $\circ / Y_{0}$ & O/1T & $0 / T_{4}$ & o/kr & جِند جملهاى & \\
\hline O/TY & $\circ / \Gamma_{0}$ & $\circ / \Lambda$ & $\circ / 1 \circ r$ & $\circ / \mu y$ & $\circ / Y_{0}$ & خطى & \\
\hline $0 / 119$ & $\circ / 09$ & $0 / 9 Y$ & .091 & $0 / 91$ & $0 / 90$ & $\mathrm{RBF}$ & \multirow{3}{*}{9} \\
\hline O/TA &.$/ 09$ & $\circ / 0 \Lambda$ & $\circ / 1 \circ 0$ & $\circ / 0 \wedge$ & $0 / 91$ & جند جملهاى & \\
\hline $0 / 101$ & $0 / 49$ & $\circ / 09$ & $0 /|Y|$ & $\circ / 0 \circ$ & $\circ / \Delta \wedge$ & خطى & \\
\hline opty & O/KY & $\circ / 4 Q$ & סמאום & $\circ / 40$ & $0 / 4 \wedge$ & $\mathrm{RBF}$ & \multirow{3}{*}{ V } \\
\hline$\circ / \mathcal{A} \wedge r$ & $\circ / 4 q$ & $\circ / Y_{0}$ & $0 /$ MA & o/AT & $0 / 40$ & جِند جملهاى & \\
\hline $0 / 490$ & $\circ M V$ & 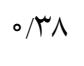 & $0 / 190$ & $\circ / \mu \wedge$ & DMY & خطى & \\
\hline$\circ / 4 V G$ & $\circ / N V$ & OKT & $0 / Y Y V$ & $\circ / 4 \circ$ & $o /$ ke & $\mathrm{RBF}$ & \multirow{3}{*}{$\wedge$} \\
\hline $0 / 4 q 0$ & $\circ / \mu x$ & $\circ / 4 q$ & ०/AND & $0 / 49$ & $0 / 41$ & جند جملهاى & \\
\hline$\circ / 01 \circ$ & OKY & ors & $0 / 491$ & س & $0 / 4 q$ & خطى & \\
\hline$\circ / r \Delta \wedge$ & $\circ / 40$ & $0 /$ Ar & $\circ / \mu \circ$ & $0 / 4 r$ & $0 / 49$ & $\mathrm{RBF}$ & \multirow{3}{*}{9} \\
\hline.$/ 490$ & 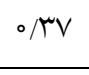 & $\circ / \psi_{0}$ & OMYY & $0 / 4 \circ$ & $0 /$ M & جند جملهاى & \\
\hline$\circ / r V 0$ & سתום & $\circ / \wedge$ & ס & $0 / \mu y$ & $\circ / \mathcal{H}^{\circ}$ & خطى & \\
\hline$\circ / \uparrow \wedge \Delta$ & $0 / 49$ & $\circ / \psi_{0}$ & $\circ / \mathcal{G}$ 。 & $0 / 4 q$ & OMY & $\mathrm{RBF}$ & \multirow{3}{*}{10} \\
\hline ./ORT & $O M Y$ & $\circ / \Gamma V$ & $\circ / 01 \circ$ & $\circ / r V$ & $\circ / Y_{0}$ & جند جملهاى & \\
\hline $0 / 901$ & $\circ / \mu \circ$ & س & $\circ / 0 \wedge 9$ & سז/ס & $0 / 49$ & خطى & \\
\hline
\end{tabular}



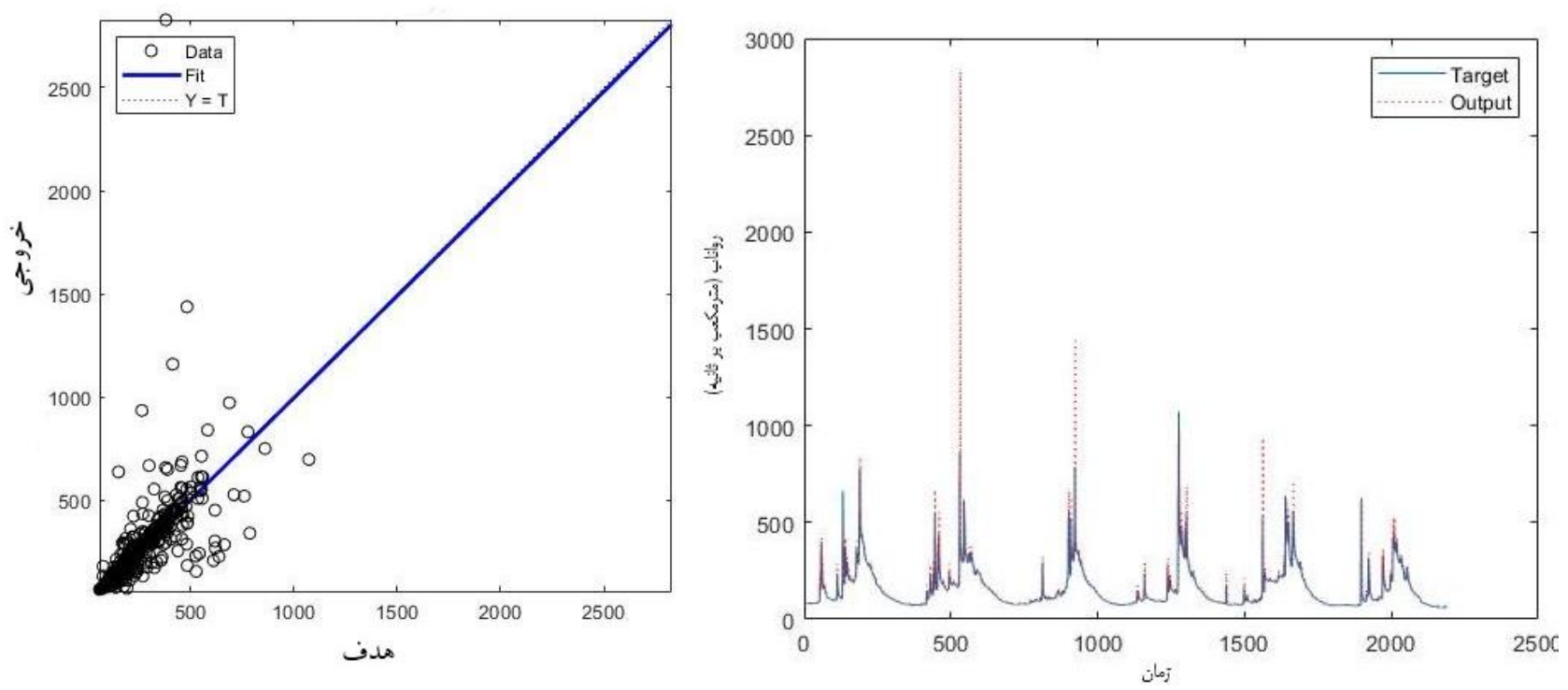

شكل צ. مقادير مشاهداتى و محاسباتى ميزان رواناب و عملكرد كرنل RBF مدل ماشين بردار يشتيبان

$$
\begin{aligned}
& \text { كارايى بهتر مدل شبكه عصبى مصنوعى نسبت بـه مــدل ماشـين } \\
& \text { بردار يشتيبان با تابع كرنل يايه شعاعى (RBF) است كه با نتسايج }
\end{aligned}
$$

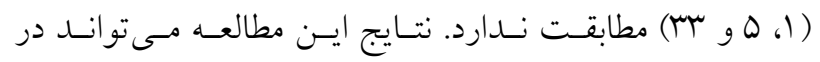

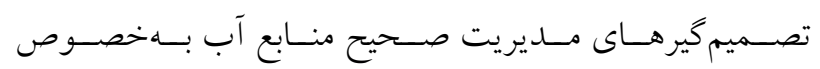

$$
\begin{aligned}
& \text { جريانهاى سـطحى، مطالعـه مربـوط بـه حساسـيت سـيلاب و } \\
& \text { هشدار سيل، انتخاب مدل بهينه برآورد رواناب ناشى از بـاران و } \\
& \text { مطالعات مربوط به مهندسى رودخانه و طراحى سازههـا بـهــار } \\
& \text { كرفته شود. }
\end{aligned}
$$

منابع مورد استفاده

1. Akhoni Pourhosseini, F. and S. Darbandi. 2018. Sofichay river runoff modeling using support vector machine and artificial neural network. Journal of Watershed Management Research 9(17): 57-66. (In Farsi).

2. ASCE Task Committee. 2000. Artificial neural networks in hydrology, II: Hydrology application. Journal of Hydrologic Engineering 5: 124-137.

3. Botsis, D., P. Latinopoulos and K. Diamantaras. 2011. Rainfall-runoff moeling using suport vector regression and artificial neural networks. 12th International Conference on Environmental Science and Technology (CEST2011), Rhodes, Greece, 8-10 September.

4. Chandwani, V., S. K. Vyas, V. Agrawal and G. Sharma. 2015. Soft computing approach for rainfall-runoff modelling: A review. Aquatic Procedia 4: 1054-1061.

5. Choubey, V., S. Mishra and S. K. Pandy. 2014. Time series data mining in real time surface runoff forecasting through support vector machine. International Journal of Computer Applications 98(3): 23-30.

6. Chua, L. H. C. and T. S. W. Wong. 2010. Improving event-based rainfall-runoff modeling using a combined artificial neural network-kinematic wave approach. Journal of Hydrology 390: 92-107.

7. Cristianini, N. and J. Shawe-Taylor. 2000. An Introduction to Support Vector Machines. Cambridge University Press, New York.

8. Dastorani, M. T., H. Sharifi Darani, A. Talebi and A. Moghadamnia. 2011. Evaluation of the application of artificial 
neural networks and adaptive neuro-fuzzy inference systems for rainfall-runoff modelling in zayandehrood dam basin. Journal of Water and Wastewater 4: 114-125. (In Farsi).

9. Dawson, C. W. and R. L. Wilby. 2001. Hydrological modelling using artificial neural networks. Progress in Physical Geography 25(1): 80-108.

10. Dehghani, N., M. Vafakhah and A. Bahremand. 2016. Rainfall-runoff modeling using artificial neural network and neuro-fuzzy inference system in Kasilian watershed. Journal of Watershed Management Research 7(13): 128-137. (In Farsi).

11. Durrant P. J. 2001. Win-GammaTM: A non-linear data analysis and modeling tool with applications to flood prediction. Ph.D. Thesis, Department of Computer Science, Cardiff University, Wales, UK.

12. Ghaderi, K., B. Motamedvaziri and P. Mahmudi. 2016. Simulation of rainfall-runoff process using artificial neural network in Kurkursar watershed, Nowshahr. First International Comprehensive Competition Conference on Engineering Sciences in Iran. September, 2016, Anzali-Iran, 1-13. (In Farsi).

13. Ghorbani, M. A., A. Azani and L. Naghipour. 2016. Comparison of the performance of support vector machine with other intelligent techniques to simulate rainfall-runoff process. Journal of Watershed Management Research 7(13): 92-103. (In Farsi).

14. Harun, S., N. I. Ahmat and A. H. M. Kassim. 2002. Artificial neural network model for rainfall runoff relationship. Journal Technology 37(B): 1-12.

15. Hosseini, S. M. and N. Mahjouri. 2016. Integrating support vector regression and a geomorphologic artificial neural network for daily rainfall-runoff modeling. Applied Soft Computing 38: 329-345.

16. Jones, A. J., A. Tsui and A. G. De Oliveira. 2002. Neural models of arbitrary chaotic systems: construction and the role of time delayed feedback in control and synchronization. Complexity International 9: 1-9.

17. Jones, A. J., S. Margetts and P. Durrant. 2001. The WinGamma User Guide. University of Wales, Cardiff.

18. Kemp, S. E., I. D. Wilson and J. A. Ware. 2004. A Tutorial on the Gamma test. International Journal of Simulation: Systems, Science and Technology 6(1-2): 67-75.

19. Kerem, H. 2006a. Generalized regression neural network in modeling river sediment yield. Advance in Engineering Software 37: 63-68.

20. Khoshhal, J., S. M. Hoseini and F. Fateminia. 2013. Simulation of rainfall-runoff using artificial neural networks (ANNs) (Case study: Faridan watershed). Geography and Environmental Planning Journal 51(3): 25-40. (In Farsi).

21. Koncar, N. 1997. Optimisation methodologies for direct inverse neurocontrol. Ph.D. Thesis, Department of Computing, University of London, London, England.

22. Kumari, P., P. Kumar and P. V. Singh. 2018. Rainfall-runoff modelling using artificial neural network and adaptive neuro-fuzzy inference system. Indian Journal of Ecology 45(2): 281-285.

23. Misra, D., T. Oommen, A. Agarwal and S. K. Mishra. 2009. Application and analysis of support vector machine based simulation for runoff and sediment yield. Biosystems Engineering 103: 527-535.

24. Mollaee, Z., J. Zahiri, S. Jalili, M. R. Ansari and A. Taghizadeh. 2018. Estimating suspended sediment concentration using remote sensing and artificial neural network (case study: Karun river). Journal of Water and Soil Science (Science and Technology of Agriculture and Natural Resources) 22(2): 249-259. (In Farsi).

25. Nourani, V. 2017. An emotional ANN (EANN) approach to modeling rainfall-runoff process. Journal of Hydrology 544: $267-277$.

26. Nourani, V. and M. Komasi. 2013. A geomorphology-based ANFIS model for multi-station modeling of rainfallrunoff process. Journal of Hydrology 490: 41-55.

27. Partovyan, A., V. Nourani and M. T. Alami. 2018. Noise injection- denoising techniques to improve artificial intelligence-based rainfall- runoff modeling. Water Engineering 11(36): 81-94. (In Farsi).

28. Sharifi, A. R., Y. Dinpashoh, A. Fakheri-Fard and A. R. Moghaddamnia. 2013. Optimum combination of variables for runoff simulation in Amameh watershed using gamma test. Water and Soil Science 23(4): 59-72. (In Farsi).

29. Shrifi Garmdareh, E., M. Vafakhah and S. Eslamian. 2019. Assessment the performance of support vector machine and artificial neural network systems for regional flood frequency analysis (A case study: Namak lake watershed). Journal of Water and Soil Science (Science and Technology of Agriculture and Natural Resources) 23(1): 351-366. (In Farsi).

30. Simonovic, S. P. and S. Ahmad. 2005. An artificial neural network model for generating hydrograph from hydrometeorological parameters. Journal of Hydrology 315: 236-251.

31. Singh, V. K., P. Kumar and B. P. Singh. 2016. Rainfall-runoff modeling using artificial neural networks (ANNs) and multiple linear regression (MLR) techniques. Indian Journal of Ecology 43(2): 436-442.

32. Tsui, A. P. M. 1999. Smooth data modelling and stimulus-response via stabilization of neural chaos, Ph.D. Thesis, Department of Computing, University of London, London, England.

33. Yu, P. S., S. T. Chen and I. F. Chang. 2006. Support vector regression for real-time flood stage forecasting. Journal of Hydrology 328: 704-716. 